\title{
Structural Health Monitoring for Woven Fabric CFRP Laminates
}

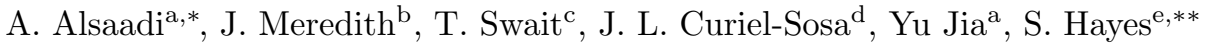 \\ ${ }^{a}$ Department of Mechanical Engineering, University of Chester, CH2 $4 \mathrm{NU}$ \\ ${ }^{b} W M G$, The University of Warwick, Coventry, CV4 7AL \\ ${ }^{c}$ Composite Centre, Advanced Manufacturing Research Centre, University of Sheffield, \\ Wallis Way, Catcliffe, S60 5TZ \\ ${ }^{d}$ Department of Mechanical Engineering, University of Sheffield, Sir Frederick Mappin, \\ Mappin St, Sheffield S1 3JD, UK \\ ${ }^{e}$ Department of Multidisciplinary Engineering Education The University of Sheffield 32 \\ Leavygreave Road Sheffield S3 7RD
}

\begin{abstract}
Structural health monitoring is directly linked to structural performance, hence it is one of the main parameters in the safety of operation. This paper presents the development of an innovative structural health monitoring system for woven fabric carbon fibre reinforced polymer (CFRP) laminates fabricated using both vacuum assisted resin transfer moulding and pre-preg technique. The sensing system combines the ability to monitor strain due to applied loads, as well as to detect, and assess damage due to low velocity impact events. Bending loads were applied on a beam-type specimen and changes in electrical resistance, due to piezoresistivity of carbon fibres, were monitored. The change in electrical resistance was a function of applied load and reversible up to $0.13 \%$ strain. Two thicknesses of composite panel, 2.09 (vacuum assisted resin transfer moulding) and $1.63 \mathrm{~mm}$ (pre-preg) were made, and were subjected to a range of low velocity impact energies. The resultant damage areas, as measured using ultrasonic C-scanning, were plotted against changes in electrical resistance to provide a correlation plot of damage area against impact energy. An inverse analysis, using this correlation plot, was performed to predict the damage area from a
\end{abstract}

${ }^{*}$ Corresponding author: Ahmed Al-Saadi (a.alsaadi@chester.ac.uk)
${ }^{* *}$ Corresponding author: Simon Hayes (s.a.hayes@sheffield.ac.uk)

Preprint submitted to Composite Part B: Engineering

May 21, 2019 
known impact event. $85 \%$ accuracy in the predicted damage area was achieved in comparison with subsequent $\mathrm{C}$-scan data on the unknown damage.

Keywords: VARTM, composite structural health monitoring, strain monitoring, damage diagnosis, damage quantification, damage assessment.

\section{Introduction}

Structural health monitoring systems for carbon fibre reinforced polymer (CFRP) are experiencing a growing interest from different communities [1]. In particular, there is a growing interest within the aerospace industry where high

5 operational safety factors, minimisation of downtimes, and reduction of structural inspection costs are required 2]. For large CFRP structures, knowing the damage initiation point and severity are desirable in order to determine the operational limits. There are, however, a few requirements that inservice health monitoring sensors need to meet. For example, they must not cause damage to the CFRP structure, they must offer the possibility of being located in remote and/or inaccessible areas of a structure and they must have the ability to transmit the data to a central processing unit [3, 4]. The data must be directly associated with a physical process that is being monitored and the properties and performances of the composite are to be maintained. Also, the acquired data must compete in sensitivity with the data obtained by conventional nondestructive evaluation techniques (NDE), such as C-scan, and it must also cover a sufficient area of a structure to enable the whole structure to be satisfactory analysed .

Few techniques have been proposed in literature, such as thermography, acoustic emission, and fibre optics [5, 6, 17. The thermography method is used to examine subsurface damage, the technique uses energy radiated from the composite surface and infrared camera to monitor heat flux at composite material surfaces [8]. There are many limitations for this technique, such as the thermal data requires sophisticated analysis techniques and highly skilled oper- 
ators. It is also difficult to adopt this technique in large and complex structures, cost of equipment and most importantly it detects damage that only makes a measurable change in thermal properties and thermal losses due to emissivity [9] 10. Acoustic emission monitoring technique is built upon the principle that deformation or damage, i.e. matrix cracking, fibre rupture, emits an au-

so dible sounds that can be collected and analysed [11. Monitoring spontaneous noise, which is generated in composite materials due to applying loading and damage can be detected, located and characterised [12, 13. However, each probe in this technique requires a dedicated digital signal processor (DSP) with an internal analogue-to-digital converter (ADC) and that adds more cost to this 35 approach [14. Fibre-optic sensors have also been studied extensively as structural health monitoring tools [15]. Fibre-optic sensors use the optical properties, such as light intensity, wavelength, phase or state of polarisation to measure strain or detect damage in composite structures [16]. There are some difficulties associated with using fibre-optic sensors, for instance to monitor strain within

40 the structure requires a perfect bonding between the fibres and the composite structures. Due to their sensitivity to environment conditions, e.g. moisture, temperature, need to be encapsulated by a polymer sheath, this in turn causes local distortions and resin-rich regions [17. Few problems arise when adopting fibre-optic sensors, such as optical fibres may fracture due to bending-induced

45 tensile stresses disregarding whether the composite matrix has damaged. This technique requires complex signal processing and analysis to obtain accurate axial strains since the measured strain is three-dimensional in nature [18, 19].

Nano-materials, such as carbon nanotubes (CNT) and graphene, have been used to alter the electrical properties of non-conductive composites, e.g. glass fibre polymer reinforced (GFRP) composites [20, 21]. Analogous to CFRP laminates, the electrical properties of nanomaterial - based self-sensing composites depend on the volume fraction of the nano-particles and their dispersion. It is reported that nano-composites are able to detect the crack onset and evolution 22. Thostenson et. al. reports that nanomaterial - based sensing are able to detect nano-scale damage due to applied loads [23]. However, there are 
many manufacturing, electrical, physical, and chemical challenges associated with adopting nano-composites, such as integration, entangled aggregates, tunnelling effect, aspect ratio of nano-materials, piezoresistivity of nano-materials, and the complex interaction between nano-particles and polymer chains [24, 25].

60 From a damage mechanism aspect nano and micro-cracks open/close due to loading/unloading cycles. Electrical resistance measured using nanomaterials, such as CNT, accumulates overtime, i.e. permanent electrical resistance occurred due to crack opening, therefore quantitative comparison is difficult to make [20, 23. In spite of the fact that detecting nano and micro-cracks is important indication of damage onset, however, it is important to note that the main load-carrying element in composites is fibres and nonomaterial-based sensing provides limited information about them.

It has been suggested that the best way to overcome challenges associated with nanomaterial-based sensing composites and meet the requirements of inservice structural health monitoring is to use a material that has the ability to monitor itself [26. For CFRP laminates an electrical resistance-based structural health monitoring system is potentially applicable for manufacturing a self-monitoring material. CFRP laminates consist of at least two different components, a polymer matrix, such as an epoxy resin, which is highly insulating ${ }_{75} \rho \approx 6.6 \times 10^{16} \Omega \mathrm{cm}$, and the carbon fibre, which is highly conductive (the electrical resistivity $\rho \approx 6.6 \times 10^{-6} \Omega \mathrm{cm}[27,28]$. This makes CFRP an inherently smart material, as changes in the electrical conductivity will occur as deformation or damage occur within the structure 29] 30] 31. It also means that electrical conductivity measurements in CFRP laminates have the potential to out-perform other methods, such as fibre optics, thermography, and acoustic methods, as it employs carbon fibres themselves as the sensing element, removing the need for additional sensors to be added [32, 33, $[5]$.

The conductivity in carbon fibre reinforced composites is complex in nature, but in order to understand the operation of self-sensing systems it needs to ${ }_{85}$ be considered 34]. Notably, the crimp nature of carbon fibres causes non-zero electrical conductivity in the through-thickness directions of woven fabric CFRP 
laminates due to a large network that is formed by fibre-fibre contacts, as shown in Figure 1. However, the electrical conductivity of a CFRP laminate in the through-thickness direction is much lower than the electrical conductivity in the fibre direction [35]. Studies, such as [36], have experimentally revealed the ratio between electric conductivity in the through-thickness direction $\rho_{t}$ to the fibre direction $\rho_{o}, \rho_{t} / \rho_{o}=26.31 \times 10^{-5}$ for a continuous CFRP laminates with a fibre volume fraction of 0.62 . This is attributed to a thin resin rich layer that exists between adjacent plies in a laminate.

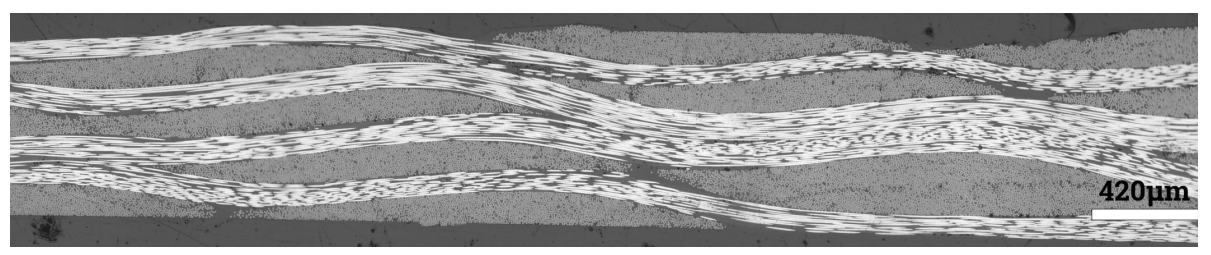

Figure 1: Optical microscope image shows through - thickness fibre - fibre contacts due to the waviness of carbon fibres in a CFRP laminate.

The features of interest (i.e. strain monitoring, damage monitoring, and damage detection) determine the type of electrical currents being used. Direct current (DC) is suitable to monitor fibre fractures and delamination [37] [38], since those types of damage produce a measurable change in electrical resistance. While alternative current (AC) may be used to monitor matrix cracks, transverse cracks, fibre/matrix debonding, and delamination [39] 40]. As well as being conductive, fibres can also display other effects when loaded Table1. For example, applying a tensile load on CFRP laminates will decrease the diameter and increase the length of carbon fibres consequently that would increase the resistance of carbon fibre due to piezoresistivity property [28]. This property increases the attractiveness of the carbon fibre as sensor systems since it directly indicates damage (and/or strain in CFRP laminates (permanent changes, i.e. fibre damage) and/or strain (via reversible changes as a result of piezoresistivity) in CFRP laminates [41]. Two-probe and four-probe measurement techniques are the most common types to measure the electrical resistance as shown in Table 1. Four-probe is more favourable as it eliminates the contact resistance 
from the measured resistance. Due to the practicalities of attaching reliable electrical contacts to CFRP composite, the contact resistance can be significant, so removal of this potential source of error is valuable; it can also present subsurface behaviour [42, 43]. This paper presents for the first time an electri-

Table 1: Summary of most important parameters effecting on the effectiveness of the electrical resistance-based monitoring systems.

\begin{tabular}{cccccc}
\hline $\begin{array}{c}\text { CFRP } \\
\text { type }\end{array}$ & $\begin{array}{c}\text { Test } \\
\text { type }\end{array}$ & $\begin{array}{c}\mathrm{DC} \\
(\mathrm{mA})\end{array}$ & $\begin{array}{c}\text { Measurement } \\
\text { system }\end{array}$ & $\left(\Delta R / R_{o}\right) \%$ & References \\
\hline$[0 / 90]_{s}$ & Bending & 10 & 2-probe & 9 & {$[3]$} \\
\hline$[0]_{8}$ & Tensile & 50 & 2-probe & 4 & {$[38]$} \\
\hline$[90]$ & Fatigue & 1 & 4-probe & $1.6-3$ & {$[44]$} \\
\hline$[0 / 90]_{2 s}$ & Indentation & 30 & 4-probe & 0.01 & {$[40]$} \\
\hline$[90 / 0]_{2 s}$ & Impact & 0.5 & 2-probe & 0.14 & {$[45]$} \\
\hline$[0 / \pm 45 / 90]_{2 s}$ & Impact & vary & 4-probe & 0.672 & {$[4]$} \\
\hline$[0]_{18}$ & Mode I & 250 & 4-probe & $0-30$ & {$[4]$} \\
\hline
\end{tabular}

cal resistance-based structural health monitoring system in woven fabric carbon fibre composite laminates fabricated by vacuum assisted resin transfer moulding (VARTM) as well as autoclave processing techniques. A four-probe method was adopted to monitor strain due to bending loads and to detect and quantify damage due to low velocity impact energy.

\section{Methodology}

\subsection{Materials and Fabrication Techniques}

Two types of CFRP laminates were manufactured. Prepreg samples used VTC401 $2 \times 2$ twill weave carbon fibres (Toray FT300B) with areal weight 275 gsm (SHD composite Materials, UK). This was cut into sheets and hand laid onto toughened glass sheet and then cured in an autoclave at $120^{\circ} \mathrm{C}$ for $45 \mathrm{~min}$ under $606 \mathrm{kPa}$ and then post cured at $135^{\circ} \mathrm{C}$ for $120 \mathrm{~min}$. VARTM used Tairyfil TC-35 $2 \times 2 \mathrm{~mm}$ twill weave carbon fibres with areal weight $200 \mathrm{gsm}$ (Formosa, Taiwan) and ultralow viscosity epoxy resin (IN-2 Epoxy resin, Easy Composites, 
UK) were used. The setup for the VARTM is illustrated in Figure2, the CFRP laminates were left to cure at the room temperature for $24 \mathrm{~h}$ and then post cured in an oven (Heraeus Instruments $\mathrm{GmbH}$, Germany) at $40^{\circ} \mathrm{C}$ for 6 hthen $50{ }^{\circ} \mathrm{C}$ for $6 \mathrm{~h}$ and then $60^{\circ} \mathrm{C}$ for $6 \mathrm{~h}$.

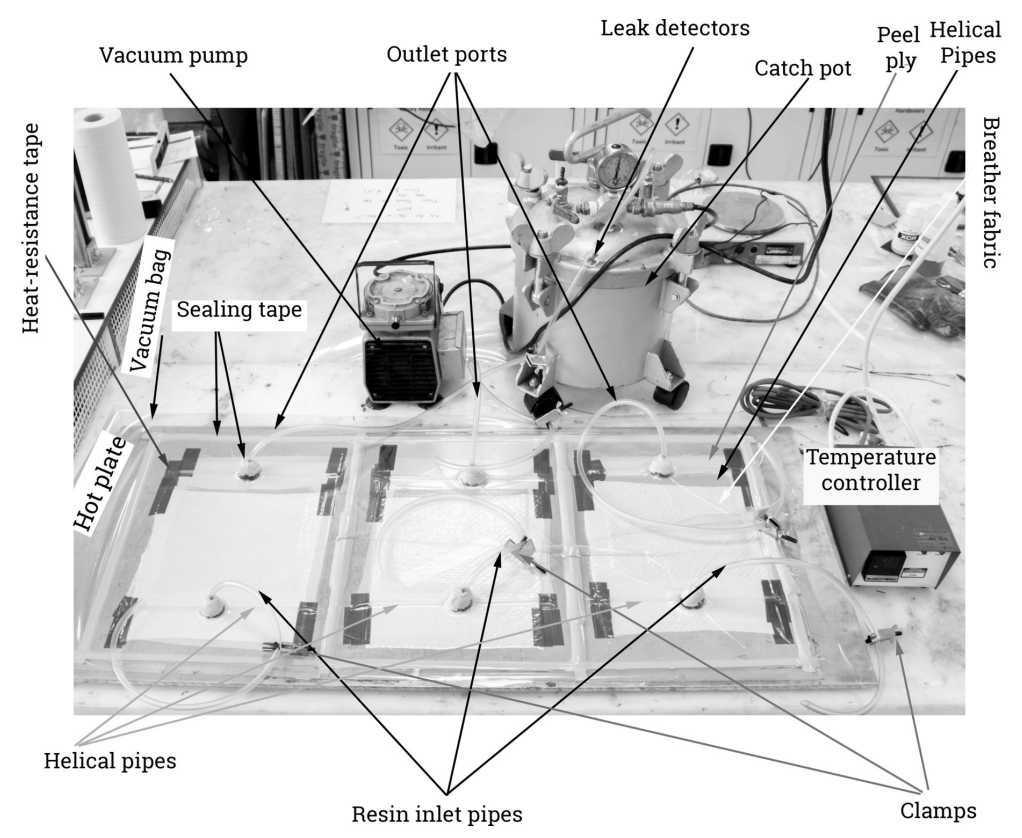

Figure 2: A typical vacuum assisted resin transfer moulding set-up.

The main goal of this study is to make a reliable, robust, repeatable and practical structural health monitoring system. Therefore, it was decided to employ sensing mats made from flexible PCB materials in order to create reproducible and reliable connection to the composite. Pyralux FR8510R (DuPont, USA) was used to make the sensing mats using photolithographic technique [48, 49], as illustrated in the following steps:

1. Sensing patterns were designed using photo editor software (Adobe Pho140 toshop) as shown in Figure $3 \mathrm{a}$ and b.

2. A photosensitive film (dry film) (Mega Electronics, UK) was applied onto the copper side of the Pyralux FR8510R as shown in Figure 3.

3. A layer of Pyralux FR8510R and the photo-sensitive film were cut by a 
pair of scissors to desired dimensions as shown in Table 2 The dry film was

cut into bigger sizes than the Pyralux FR8510R sheets to ease removing the plastic film that was required prior to the next step (developing stage).

4. The combination of Pyralux FR8510R with the dry film were put inside a vacuum bag and then they were placed in an oven, (Heraeus Instruments GmbH, Germany) at $60^{\circ} \mathrm{C}$ under $92 \mathrm{kPa}$ of vacuum pressure for two hours; heating rate of $3-5^{\circ} \mathrm{C} \mathrm{min}-1$ was sufficient to maintain the light sensitivity of the dry film while ensuring good adhesion.

5. The combination of Pyralux FR8510R and the dry film was exposed to UV light using a UV exposure unit (RS, UK) for $40 \mathrm{~s}$, with the mask that was produced in step 1 being used to protect areas of copper that were needed for sensor system, Figure 3 .

6. UV exposed sheets were developed by placing them in a basket holder and immersing them in a potassium carbonate solution (Dry Film Photoresist Developer, MEGA Electronics, UK). Potassium carbonate was diluted in distilled water according to the manufacturer recommendations. The development process occurred at $38^{\circ} \mathrm{C}$ in the $\mathrm{PCB}$ etcher for $15 \mathrm{~min}$. Since the artworks were negative, so the dry film removed from all areas apart from areas that were exposed to UV light (electrode, track and pad areas).

7. The developed sensing mats were taken out of the developing tank in the $\mathrm{PCB}$ processing station and washed by low pressure water jet at the room temperature.

8. The developed and washed sensing mats were then placed into the basket holder and immersed in the etching tank. The PCB etchant, $40 \%$ ferric chloride solution UN2582 (UN2582, MEGA Electronics, UK) was used to etch the developed sensing mats. Ferric chloride was mixed with the distilled water, with a mixing ratio of 3:1. The etching process occurred at $38^{\circ} \mathrm{C}$ of $5 \mathrm{~min}$ as shown in Figure $3 \mathrm{~d}$.

9. A cleaning grade acetone (Sigma Aldrich, UK) was used to strip the remaining dry film, by immersing the etched sensing mats in acetone for 10 min then a brush was used to scrub the sensing mats to remove the 
remaining polymer.

Table 2: Sensing mat dimensions

\begin{tabular}{cccccc}
\hline $\begin{array}{c}\text { Sensing } \\
\text { mat }\end{array}$ & $\begin{array}{c}\text { Pyralux } \\
\text { FR8510R } \\
\text { dimension } \\
(\mathrm{mm})\end{array}$ & $\begin{array}{c}\text { Dry } \\
\text { dimension } \\
(\mathrm{mm})\end{array}$ & $\begin{array}{c}\text { Coverlay } \\
\text { FR0110 } \\
\text { dimension } \\
(\mathrm{mm})\end{array}$ & $\begin{array}{c}\text { Sensing } \\
\text { mat } \\
\text { size } \\
(\mathrm{mm})\end{array}$ & $\begin{array}{c}\text { Sensing } \\
\text { Electrode } \\
\text { dimension } \\
(\mathrm{mm})\end{array}$ \\
\hline Mat 1 & $235 \times 200$ & $250 \times 160$ & $235 \times 140$ & $200 \times 200$ & $10 \times 10$ \\
\hline Mat 2 & $235 \times 200$ & $250 \times 160$ & $35 \times 140$ & $00 \times 200$ & $20 \times 20$ \\
\hline
\end{tabular}

A cover layer was used in this study to isolate tracks in sensing mats from making contact with the CFRP laminates in desired locations. The coverlay used was Pyralux FR 0110 Coverlay (DuPont, USA) consisting of a $25 \mu \mathrm{m}$ thick layer of polyimide covered with a $25 \mu \mathrm{m}$ thick of $\beta$-staged acrylic adhesive. $\beta$ staged acrylic adhesive's main function is to join the coverlay to the etched sensing mats. Sensing mats made from Pyralux FR8510R reduced the amount of wiring required. The combination of sensing mat and coverlay was enveloped in a vacuum bag and then placed in an oven (Heraeus Instruments $\mathrm{GmbH}$, Germany) to cure the $\beta$-staged acrylic adhesive at $70^{\circ} \mathrm{C}$ for $2 \mathrm{~h}$ under $92 \mathrm{kPa}$ of pressure. After cure, the peel strength between the coverlay FR0110 and the Pyralux FR8510R was $1.6 \mathrm{~N} / \mathrm{m}$ according to manufacturer datasheet as described in test manual of IPC test methods [50]. The final sensing mat is shown in Figure 3 e. The sensing mat was then attached to the composite laminates using a Silver-Epoxy adhesive (8331S, MG Chemicals).

\subsection{Electrical Resistivity of Woven Fabric CFRP Laminates}

The electrical conductivity of $2 \times 2$ twill weave CFRP laminates in the warp and weft directions are equal,$\rho_{\text {warp }}=\rho_{\text {weft }}$, however, through-thickness electrical resistivity $\rho_{t} \approx 10^{4} \cdot \rho_{\text {weft }}$ [35, [51]. Two types of carbon fibres were adopted in this study being Toray FT300B for autoclave processing and Tairyfil TC-35 for VARTM processing techniques. The electrical resistivity of those 


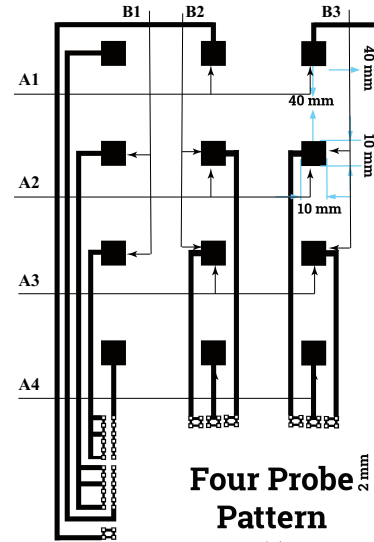

(a)

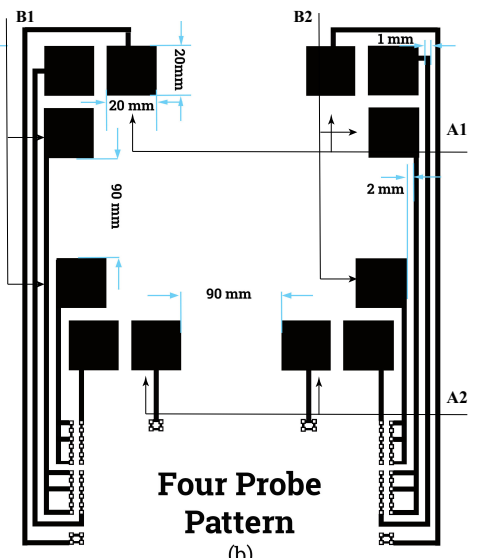

(b)

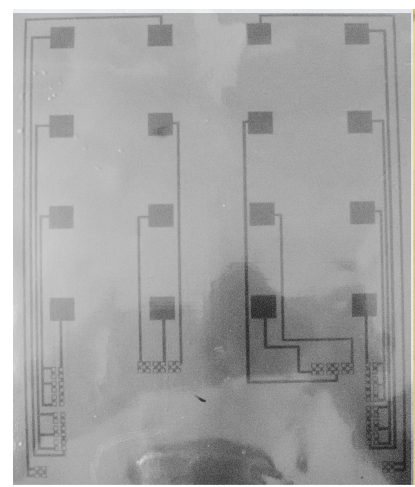

(c)

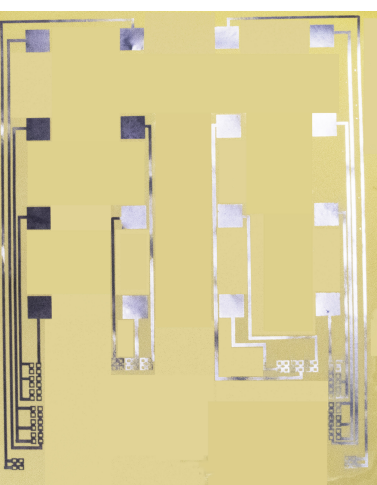

(d)

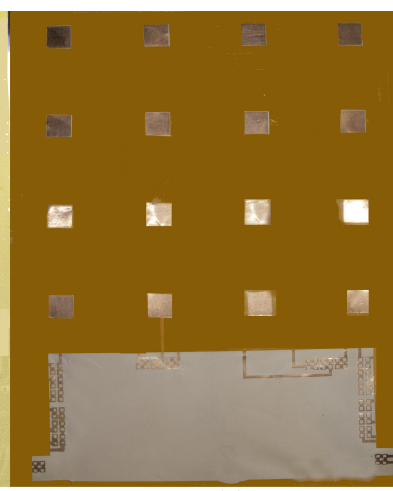

(e)

Figure 3: Sensing pattern designs are shown in (a) pattern used to manufacture sensing mat 1 , and (b) pattern used to manufacture sensing mat 2. Steps to fabricate sensing mats are shown in (c) a flexible circuit board after exposing to UV light, (d) sensing mat passing the developing stage, and (e) ready to use sensing mat 1.

carbon fibres being $1.7 \times 10^{-2}$ and $1.73 \times 10^{-2} \Omega \mathrm{mm}$ respectively [52, 53]. Figure 5 shows optical microscopy images of fabricated composite laminates. It can be seen that CFRP laminates made using the autoclave processing techniques (Figure 5 a) have a higher density of fibre-fibre contact between adjacent plies, therefore they had a lower through-thickness resistivity than their equivalents made using VARTM processing technique (Figure 5 b), those being 3.3 and $3.6 \Omega \mathrm{mm}$ respectively. It is important to mention that the disruption of fibrefibre contact network between adjacent plies in laminate will cause the change 


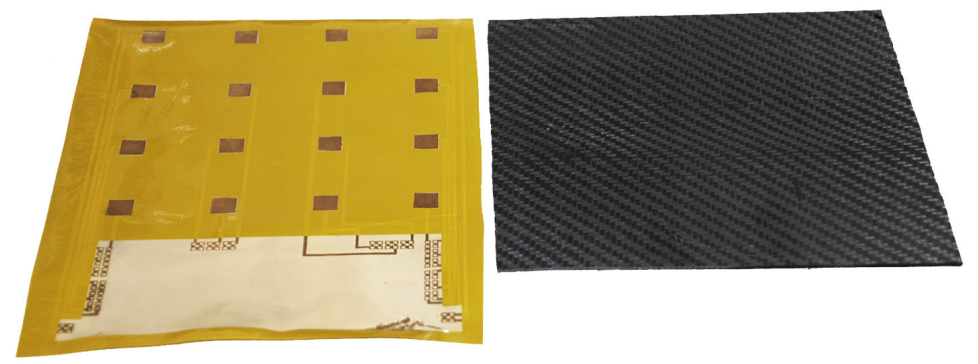

Figure 4: CFRP panel on the right and on the left is sensing mat 1 to be attached onto CFRP panel using a Silver-Epoxy conductive adhesive.

in $R_{t}$, while the change in $R_{\text {in-plane }}$ occurs due to piezoresistivity of carbon fibres.

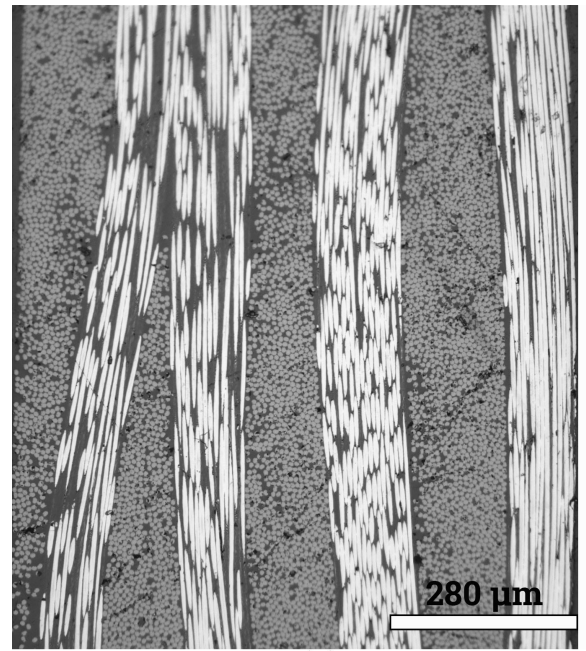

(a)

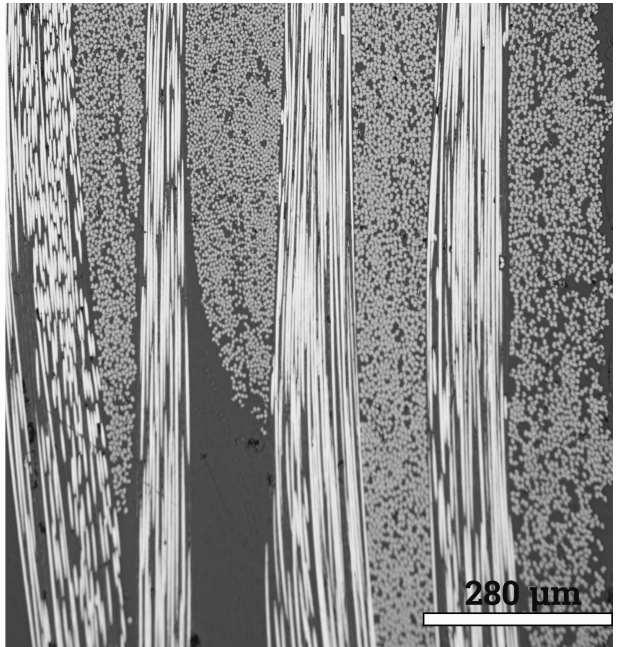

(b)

Figure 5: Cross-section of CFRP laminates manufactured using (a) autoclave and (b) VARTM processing techniques. The electrical contacts between adjacent plies occurred due to fibre-fibre contacts between adjacent plies, however, the fibre fibre contact density in a is higher than $b$.

The electrical resistance of woven fabric CFRP laminates $(\mathrm{R})$ can be described using Ohm's law

$$
R=\frac{V}{I}
$$


Where I is a direct electrical current (DC) in Amperes (A) and V is voltage in Volt (V). According to Equation 1, the amount of current that flows through a carbon fibre is inversely proportional to its resistance; the electrical resistance in turn depends upon chemical compositions of materials, fibre diameter, and

\subsection{Data Acquisition System}

Modules of NI9219 (National instrument, USA) were installed in a NI cDAQ9172 (National instruments, USA) chassis. A four-probe electrical resistance 
headers, soldering materials, and lead wires) are neglected since there is only a small amount or none of an electric current flowing across the electrical potential terminals [55, 56]. The data collection was triggered using a dedicated software that was written in LabView. The terminals in the NI9219 modules were executed consecutively to avoid interference between the excited terminal and the others during the data collection process. In LabView structural loops were used to obtain electrical resistance and to avoid interference. Each loop measures the electrical resistance between a certain pair of electrodes while the other channels in the same loop were configured to measure voltage. This strategy was successful to avoid the electrical interference between channels if they were set to measure the electrical resistance between all electrodes at the same time. A $500 \mu \mathrm{A}$ of a direct electrical current was injected into the CFRP laminates. The Ohmic heat generated was as low as $1.635 \times 10^{-5} \mathrm{~W}$, this can be ignored since the short period of testing time, few seconds, as well as the low current will not allow heat accumulation.

It was found that this amount of the electrical current did not generate Ohmic heating during electrical tests.

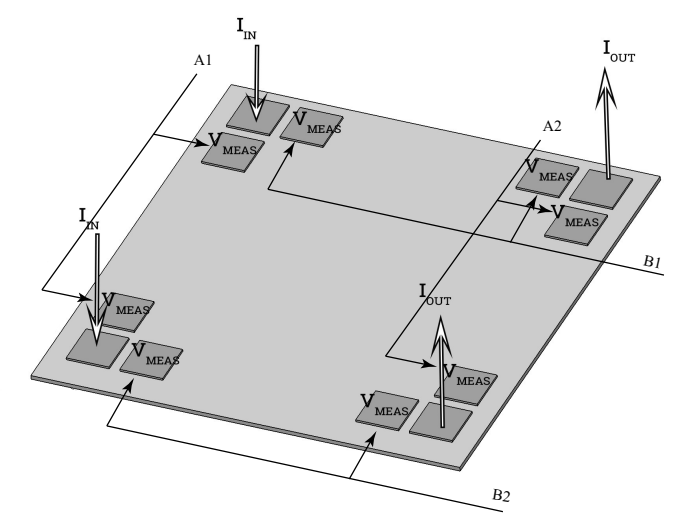

Figure 6: The measurement map of electrical resistance in CFRP plates using sensing mat 2.

The global electrical resistance of CFRP plates when sensing mat $1\left(\xi_{1}\right)$ was 
used is given in Equation 2,

$$
\xi_{1}=\frac{\sum_{A 1}^{A 4}\left(\Delta R / R_{o}\right)+\sum_{B 1}^{B 4}\left(\Delta R / R_{o}\right)}{8} * 100
$$

Since the spacing distance between adjacent electrodes in sensing mat 2 is higher than sensing mat 1, therefore the global electrical resistance when sensing mat 2 was attached to the CFRP laminates can be expressed in Equation 3

$$
\xi_{2}=\frac{\sum_{A 1}^{A 2}\left(\Delta R / R_{o}\right)+\sum_{B 1}^{B 2}\left(\Delta R / R_{o}\right)}{4} * 100
$$

\subsection{Bending Test}

The bending test was carried out according to ASTM D7264/D7264M and ASTM 6856/D6856M, however the span length of specimens was $200 \mathrm{~mm}$ as shown in Figure 7. The specimens were subjected to four loading cycles and the

\subsection{Low Velocity Impact Test}

Damage was generated using a drop-weight impact tester according to ASTM D7136/D7136M-15. Where a flat composite plate of $200 \times 200 \times t \mathrm{~mm}(\mathrm{t}$ was $1.63 \mathrm{~mm}$ for autoclave processing panels and $2.09 \mathrm{~mm}$ for VARTM panels) was subjected to a through-thickness impact with a hemispherical impactor, $13 \mathrm{~mm}$ in diameter. The carbon fibre composite laminate panel was placed onto a steel plate, which had an orifice of $50 \mathrm{~mm}$ in diameter, the panel was clamped tightly on the horizontal plane using G-clamps. The incident velocity of the impact was measured using a magnetic sensor that was installed just above the target. The incident energy (kinetic energy (K.E)) was calculated using the following formula

$$
K . E=\frac{1}{2} \cdot m \cdot v^{2}
$$




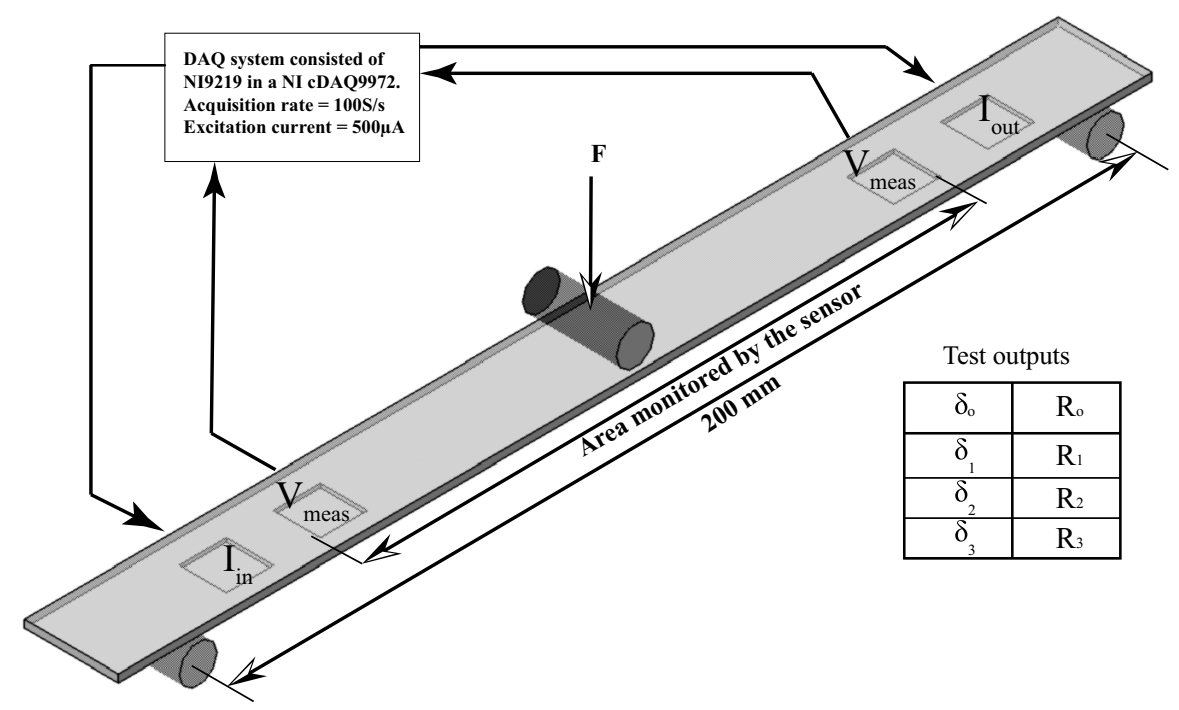

Figure 7: Schematic illustrates bending - electrical resistance testing set up. The test monitors deflection - electrical resistance of CFRP laminates. The bending test was undertaken according to ASTM D7264/D7264M and ASTM 6856/D6856M.

Where $m$ is the weight of the impactor and the carriage $(1.456 \mathrm{~kg})$, and $v$ is the incident velocity $\left(\mathrm{m} / \mathrm{s}^{2}\right)$

\subsection{C-scanning}

A hand-held C-scan camera (Dolphitech, Norway) was deployed to measure the damage area. The damage area was estimated by importing C-scan images to a photo editor (Adobe Photoshop) and then the number of pixels in the damage region were related to the damage area.

\section{Results and Discussion}

\subsection{Strain Monitoring}

Table 3 presents electrical resistance of CFRP laminates fabricated both by VARTM and autoclave processing techniques during 3-point bending testing. $R_{o}$ is the electrical resistance when the CFRP laminates were unstrained (no deflection loads were applied), $R_{i}$ is the electrical resistance when the CFRP 
laminates were strained. The consolidation of autoclave processed laminates was higher than VARTM processed laminates, that is due to the high hydrostatic pressure in the autoclave processing technique $606 \mathrm{kPa}$ while $92 \mathrm{kPa}$ in VARTM technique [57, 58].

Using sensing mat 1, electrical resistance changes in VARTM laminate panels were reversible in cycle one and cycle two, where the maximum deflection was 2 and $4 \mathrm{~mm}$ respectively, as shown in Table 3 . However, in cycle three and four, where the maximum deflection was 6 and $8 \mathrm{~mm}$ respectively, these panels showed irreversible changes in electrical resistance of $0.017 \%$ and $0.0124 \%$ respectively. In panels fabricated via autoclave processing technique and at cycle one and two, the electrical resistance increased reversibly. However, at cycle three and four the change in electrical resistance was increased irreversibly by up to $0.02 \%$ and $0.032 \%$ respectively. This change in electrical resistance was likely attributed to minor damage where matrix cracking was heard during the test as shown in Figure 8. These matrix cracks reduce the number of fibre - fibre contacts in plies and between consecutive plies and therefore decrease the surface electrical conduction and through - thickness electrical conduction, and thus increase the electrical resistance. It was noticed that the irreversible change in electrical resistance increased when the deflection increased, which can be attributed to minor damage (matrix cracks) becoming more defined.

soo Table 3 shows the changes in electrical resistance in panels fabricated using a VARTM technique was smaller than panels fabricated using an autoclave processing technique. This is likely to be because IN - 2 Epoxy Infusion Resin was tougher than VTC 401 resin, thanks to presence of 1,6 bis (2,3-epoxypropoxy) hexane in its formula [59], although no fracture toughness testing has been done in this study. Changes in electrical resistance due to applied loads were also measured in all panels using sensing mat 2, Table 3. Cycle one and two were undetectable, therefore no change in electrical resistance occurred. The laminate showed reversible changes in electrical resistance at cycle three, while a $0.027 \%$ irreversible change in electrical resistance was observed during cycle four, this is attributed to minor matrix damage as previously with sensing mat 
1. In this study, it is therefore, observed that sensing mat 2 was less sensitive to strain monitoring and damage detection than sensing mat 1 . This is thought to be due higher spacing between sensing electrodes.

Figure 9 shows a qualitative analysis of strain monitoring for both VARTM and autoclave processing due to applied strain. Strain measurements were taken using a digital camera installed onto the testing frame as described in Section 2.5 It can be seen in the figure that the amount of change in electrical resistance was as low as $0.0025 \%$ at strain of $0.05 \%$ and it increased nonlinearly. It is important to note that the woven fabric CFRP laminates do not obey Hook's law, therefore the change in electrical resistance due to applied loads in the elastic region was nonlinear [60]. This is contrary to unidirectional CFRP laminates, where the electrical resistance increases linearly in the elastic region with the applied load [61]. At strain of $\approx 0.19 \%$ an irreversible change in electrical resistance was observed in both laminates at different percentage depending on the sensing mats. This change was attributed to matrix cracks, when the shear force exceeded the shear force of the epoxy matrix at strain of $0.25 \%$ other types of damage started to appear, such as fibre splitting, therefore the test was stopped as shown in Figure 8 Those types of damage caused higher changes in electrical resistance, see Section 3.2. The electrical resistance 330 changes reported in this study was slightly lower than L. Vertuccio et al. where $0.41 \%$ change of electrical resistance was obtained at strain of $1 \%$ 62]. This was attributed to many factors, such as the type of current, i.e AC or DC. Also the damage mechanism is entirely different, where CNT experiences irreversible change in electrical resistance due to tension. A. Sanli et al. reported a negative resistance change, i.e. negative piezoresistivity, of $-0.08 \%$ due to uniaxial compressive loads [63]. It is important to note that the nanomaterials-based sensing technique is mainly used to monitor the matrix and therefore it provides limited information about the reinforcing element.

The positive electrical resistance, i.e. positive piezoresistivity, shown in Fig340 ure 9 was attributed to the location of the sensing mat, where the mats placed on to the bottom surface of the laminate, i.e. surface under tension loading. The 
electrical resistance increased with the loading due to the increase of the alignment of the fibres and therefore decrease fibre-fibre contacts between adjacent plies.

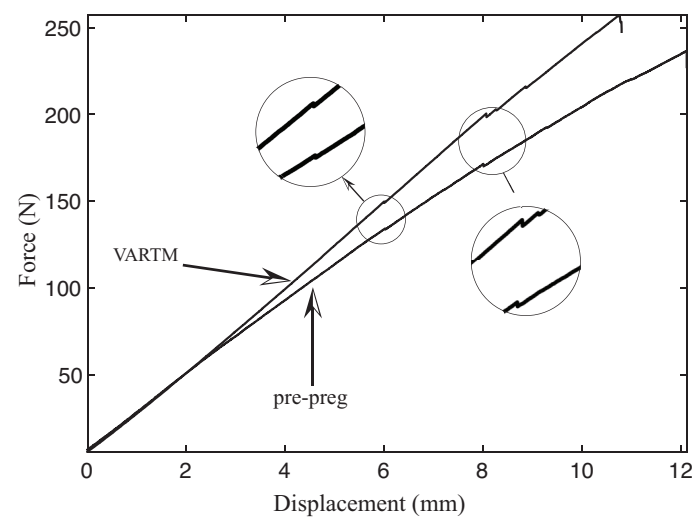

Figure 8: Force - displacement curve of CFRP laminates, the deviation in the curves at $6 \mathrm{~mm}$ and $8 \mathrm{~mm}$ were likely attributed to matrix cracking, the test was stopped when a fibre splitting occurred. Flexural Young's modulus of VARTM laminates $E_{f}=55 \mathrm{GPa}$ and $E_{f}=57 \mathrm{GPa}$ for autoclave processing laminates.

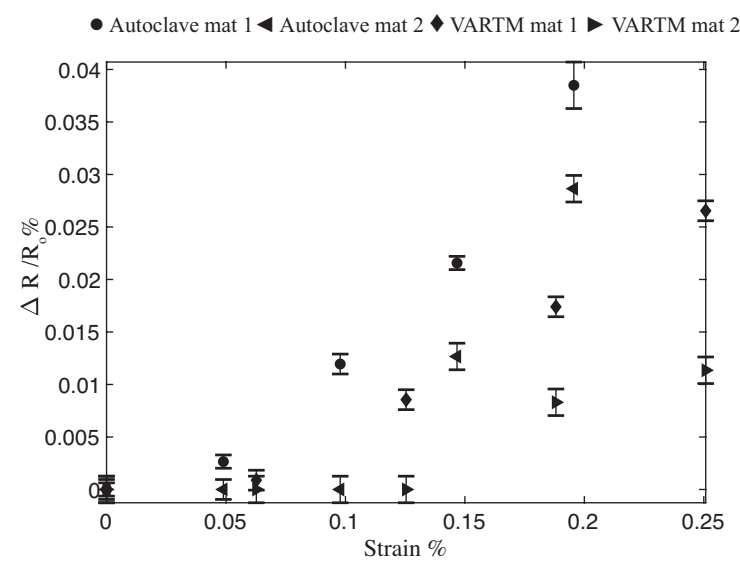

Figure 9: Electrical resistance variations due applied strain, the electrical resistance was measured when the CFRP laminates strained. Reversible electrical resistance variations were observed up to $0.18 \%$ of strain and then irreversible electrical resistance variations were noticed after a threshold of $0.19 \%$ of strain where a damage in form of matrix cracks evolved. 
Table 3: Changes in electrical resistance due to deflection at 2, 4, 6, and $8 \mathrm{~mm}$ for 2.09 and $1.63 \mathrm{~mm}$ CFRP laminates that were fabricated by VARTM and autoclave processing techniques respectively. The electrical resistance readings were acquired using both sensing mats.

\begin{tabular}{|c|c|c|c|c|c|c|c|c|c|}
\hline \multirow{3}{*}{ Cycle Number } & \multirow{3}{*}{$\delta(m m)$} & \multicolumn{4}{|c|}{ VARTM Processing Panels } & \multicolumn{3}{|c|}{ Autoclave Processing Panels } & \\
\hline & & \multicolumn{2}{|c|}{ Mat 1} & \multicolumn{2}{|c|}{ Mat 2} & \multicolumn{2}{|c|}{ Mat 1} & \multicolumn{2}{|c|}{ Mat 2} \\
\hline & & $R_{o}(\Omega)$ & $R_{i}(\Omega)$ & $R_{o}(\Omega)$ & $R_{i}(\Omega)$ & $R_{o}(\Omega)$ & $R_{i}(\Omega)$ & $R_{o}(\Omega)$ & $R_{i}(\Omega)$ \\
\hline 0 & 0 & 0.0339103 & - & 0.0590143 & - & 0.0301362 & - & 0.05132070 & - \\
\hline 1 & 2 & 0.0339103 & 0.03391060 & 0.0590143 & 0.0590143 & 0.0301362 & 0.0301370 & 0.05132070 & 0.05132070 \\
\hline 2 & 4 & 0.0339103 & 0.0339132 & 0.0590143 & 0.0590143 & 0.0301362 & 0.0301398 & 0.05132070 & 0.05132070 \\
\hline 3 & 6 & 0.0339103 & 0.0339162 & 0.0590143 & 0.0590192 & 0.0301365 & 0.0301427 & 0.05132070 & 0.05132720 \\
\hline 4 & 8 & 0.033911 & 0.0339193 & 0.0590146 & 0.059021 & 0.0301382 & 0.0301478 & 0.05132088 & 0.05133540 \\
\hline- & 0 & - & 0.03391210 & - & 0.0590150 & - & 0.0301400 & - & 0.05132145 \\
\hline
\end{tabular}

345

Chung et al. reported that negative piezoresistivity is observed when the electrical resistance measured at the compression surface [64]. This is because compression loads squeeze the matrix in the through-thickness direction causing more fibre-fibre contacts. It was also reported that piezoresistive sensors, i.e. carbon fibres, tend to be more precise to monitor strain than resistive sensors, i.e. strain gauges [61]. The sensing system proposed in this study is universal, however, other environmental variables, such as the effect of temperature and moisture on electrical resistance readings needed further investigation. In 350 order to implement the current sensing system in an aircraft structure, the presence of lighting protection metal foil in aircraft structures presents an engineering challenge that is needed to be addressed. The latter problem can be solved by applying the sensing mat onto the internal surface, this could lead to negative piezoresistivity, which is less sensitive to strain monitoring. 


\subsection{Damage Diagnosis}

The damage was diagnosed by the global variation in electrical resistance of the CFRP plates; the amount of changes in electrical resistance depended on many factors such as, the manufacturing process, the fibre volume fraction, epoxy matrix, impact energy, sensing mats, and the thickness of the laminates. Figure 10 and Figure 11 show various types of damage due to different low velocity impact energies. Figure 10 shows the damage in CFRP plates fabricated using VARTM technique; when the plate was impacted at $2 \mathrm{~J}$ in the Figure $10 \mathrm{a}$, the damage in the form of matrix cracks was generated, the damage area was $48 \mathrm{~mm}^{2}$. The absolute variation in global electrical $\Delta \xi_{1}$ was $2.5 \times 10^{-3} \Omega$. On the other hand when the CFRP plate fabricated using autoclave processing in Figure 11 and impacted at the same amount of energy damage of $71 \mathrm{~mm}^{2}$ was created, therefore a higher variation in electrical resistance occurred being $3.1 \times 10^{-3} \Omega$. When the impact energy increased to $3.5 \mathrm{~J}$, the damage area
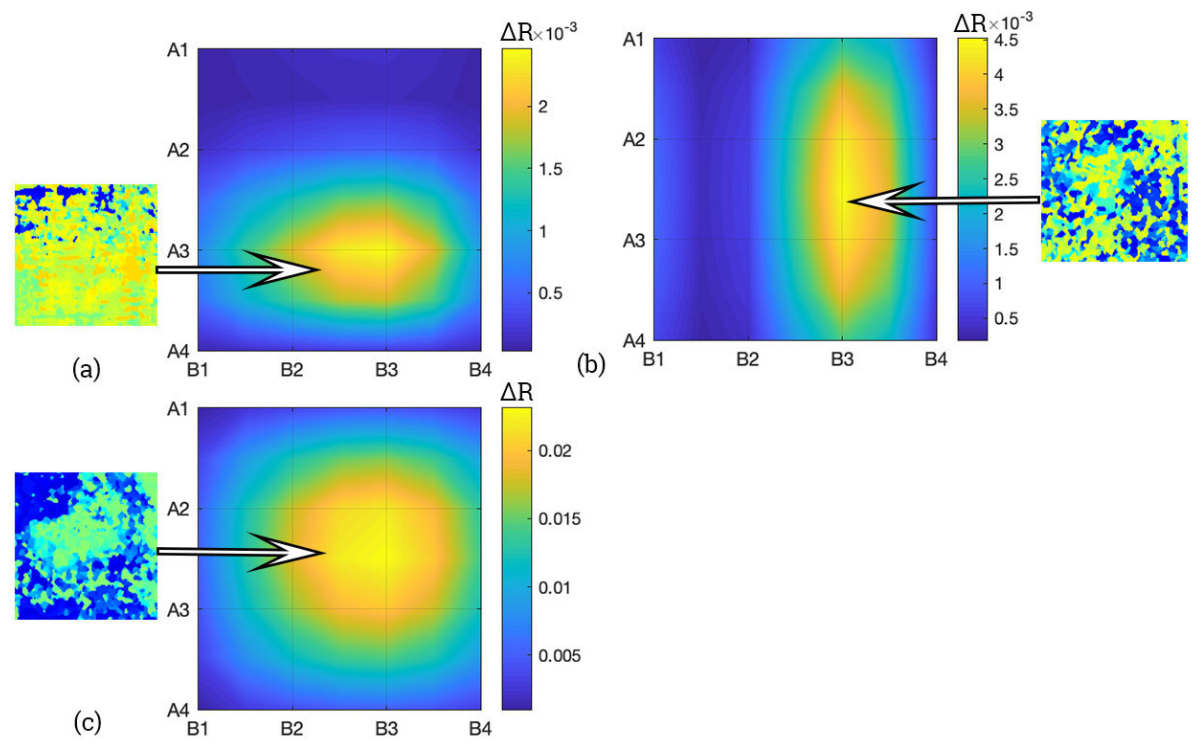

Figure 10: Damage location in VARTM panels that had carbon fibre volume fraction of $47 \%$ and they were impacted at room temperature at (a) $2 \mathrm{~J}$, (b) $3.5 \mathrm{~J}$, and (c) $5 \mathrm{~J}$. The C-scan images beside each graph show the damage profile. 

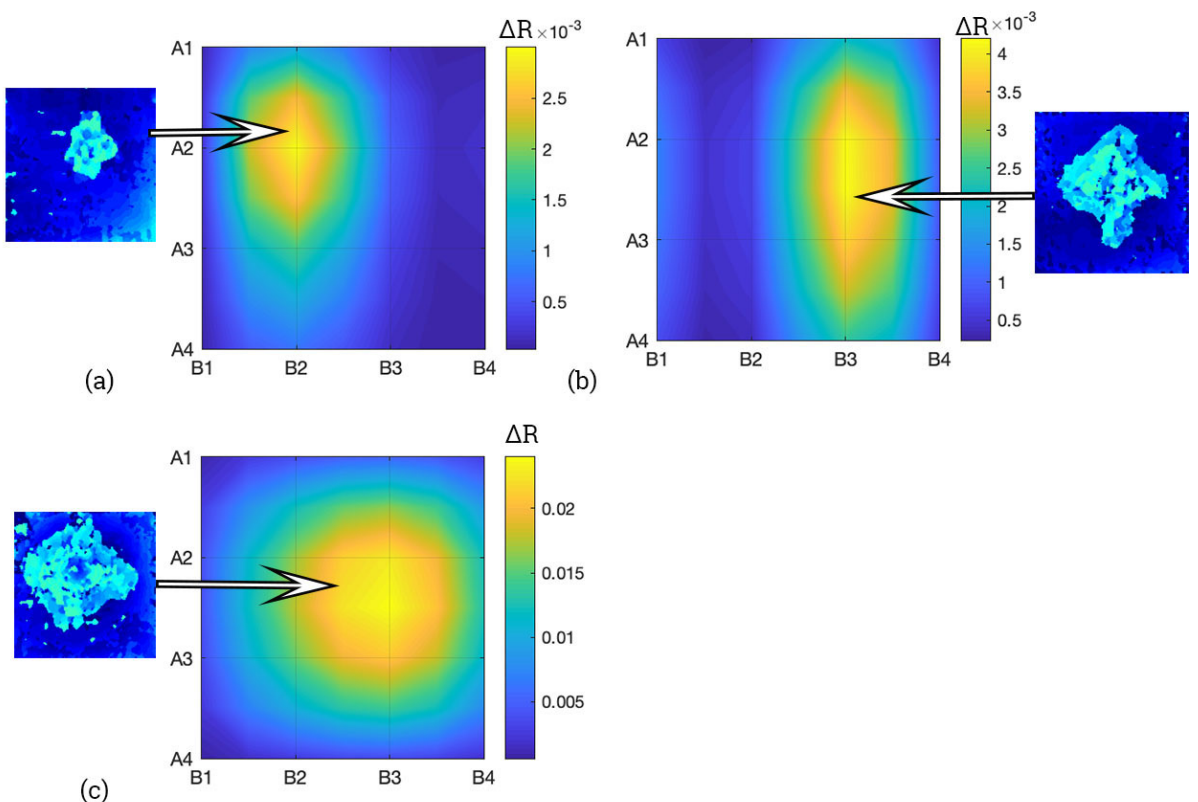

(c)

Figure 11: Damage location in autoclave processing panels that had carbon fibre volume fraction of $50 \%$ and they were impacted at room temperature at (a) $2 \mathrm{~J}$, (b) $3.5 \mathrm{~J}$, and (c) 5 J. The C-scan images beside each graph show the damage profile.

increased to 107 and $250 \mathrm{~mm}^{2}$ in CFRP panels fabricated using VARTM and autoclave processing respectively. C-scanning images showed that damage in form of matrix cracks and delamination occurred. In CFRP panel fabricated using VARTM panels the damage area was significantly smaller than damage area in their equivalents fabricated by autoclave processing. This can be attributed to two main factors that were higher fabrication pressure as discussed in Section 3.1 as well as the toughened epoxy matrix. IN-2 epoxy infusion resin, which was used to fabricate CFRP plate in VARTM technique, had a toughening component in its structure (epoxypropoxy hexane) that in turn helped to reduce damage area. The variations in electrical resistance due to damage occurrence in Figure $10 \mathrm{~b}$ and Figure $11 \mathrm{~b}$ were $4.5 \times 10^{-3}$ and $4 \times 10^{-3} \Omega$ respectively. In spite of the fact that the damage area in Figure 10p was smaller than Figure 11 $\mathrm{p}$, the change in electrical resistance was higher, and this was attributed to the 
Therefore, it is supposed that a small damage area can interrupt those contacts and that in turn caused higher changes in electrical resistance. When the impact energy increased to $5 \mathrm{~J}$, all types of damage (matrix cracks, delamination, and fibre breakage) were observed in both panels, the damage area was 138 and

ing respectively. However, the variation in electrical resistance were similar in both panels at around $0.024 \Omega$.

\subsection{Damage Assessment}

The damage areas measured by $\mathrm{C}$-scan were plotted against the percentage of global electrical resistance variations as shown in Figure 12. It was found that low impact energy levels produced measurable changes in electrical resistance of CFRP laminates using both sensing mats, however, all damage types were clearly defined and approximately quantified when sensing mat 1 was used. Figure 12 and Figure $12 \mathrm{~b}$ present the relationship between the global electrical 395 resistance variations of panels $\xi$ and damage areas. It was evident that both sensing mats were able to identify damage. However, it can be seen that changes in electrical resistance in sensing mat 2 were lower than changes in electrical resistance in sensing mat 1 , in spite of the fact that the electrode area of sensing mat 2 was higher than sensing mat 1 being $400 \mathrm{~mm}^{2}$ and $100 \mathrm{~mm}^{2}$ respectively. That in turn means sensing mat 2 made contacts with higher number of carbon fibres and since the distance between electrodes in mat 2 was higher $90 \mathrm{~mm}$ while the distance between the electrodes in mat 1 was $40 \mathrm{~mm}$. This helped the electric current to find alternative paths to follow when damage occurred, making the reduction in electrical resistance less obvious than in mat 1. According to current 405 density law, increasing the surface area of the electrode decreases the current density, therefore the sensitivity of the sensor decreases.

\subsection{Inverse Analysis}

In an attempt to quantify damage using electrical resistance data, an inverse analysis was undertaken as shown in Figure 12. The CFRP laminate was sub- 


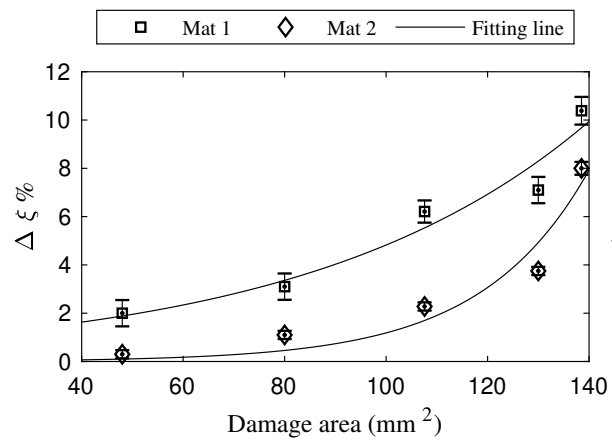

(a)

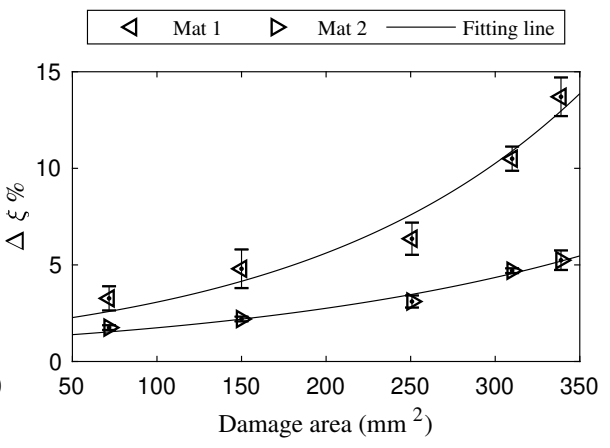

(b)

Figure 12: Changes in electrical resistance due to low velocity impact damage in CFRP panels fabricated by (a) VARTM and (b) autoclave processing techniques.

jected to a $3 \mathrm{~J}$ of low velocity impact energy. The global electrical resistance change $\xi$ was measured using sensing mat 1 ; it was found that $\xi$ equals to 3 and $2.2 \%$ in CFRP panels fabricated using autoclave processing and VARTM techniques respectively. These values were projected on the fitting lines in Figure 12 a and Figure $12 \mathrm{~b}$, the damage area was estimated to be 85 and $58 \mathrm{~mm}^{2}$ respectively. Damage was then measured using a non-destructive test (C-scan test) and the damaged area was found to be 100 and $63 \mathrm{~mm}^{2}$ in CFRP panels fabricated using autoclave processing and VARTM techniques respectively. The error of estimation was found to be 15 and $5 \mathrm{~mm}^{2}$ using sensing mat 1 . When sensing mat 2 was used, the changes in electrical resistance were 1.8 and $0.93 \%$ in CFRP panels fabricated using autoclave processing and VARTM respectively. The error of estimation was found to be 68 and $78 \%$. The error of estimations were attributed to the negative electric current at the panel surface. Ideally in metals the electric current flows from the negative electrode to the positive electrode directly. However, in CFRP laminates due to orthotropic nature of laminates the electric current flows from the negative electrode to the positive electrode, but electric current passes the positive electrode and then flows back to the positive electrode [35]. This longer path causes a reduction in electrical resistance changes due to damage, this means the actual electrical resistance 
changes were higher than the measured ones, therefore the damage area predicted using electrical resistance changes was smaller than the actual damaged area. Also the fitting lines affect on the accuracy of the estimation, and to obtain a more accurate fitting line a large set of experiments would be required.

\section{Conclusion}

Surface mounted sensing mats are able to not only monitor strain but also detect, locate, and assess damage severity effectively on both the surface and thorough-thickness of CFRP panels. The design of sensing mats is important since, the spacing between sensors has a greater impact on electrical resistance readings than the sizes of the sensing electrodes. The baseline electrical resistance readings using sensing mat 1 (spacing between sensors $40 \mathrm{~mm}$ and sensor size $100 \mathrm{~mm}^{2}$ ) was $55 \%$ lower than electrical resistance readings using sensing mat 2 (spacing between sensors $90 \mathrm{~mm}$ and sensor size $400 \mathrm{~mm}^{2}$ ). There was a damage area threshold below which the presented sensing technique was less effective, this threshold increased when the spacing between electrodes increased. A direct correlation between changes in electrical resistance and damage size has been found, where the severity of damage can be predicted from changes in electrical resistance of CFRP panels. However, the accuracy of the damage location depended on the impact energy, the higher the impact energy the higher the variation in electrical resistance was. The effect of fibre-fibre contacts between adjacent plies was the highest when damage severity was assessed than other parameters as it caused a negative electrical flow, therefore, it increased the error of estimation. The output of the current system is a two-dimensional in-plane map of damage with an estimated error between 15 to $78 \%$ depending on variables above. This work demonstrates a novel in-situ sensing system able to determine the location and approximate size of damage with a level of accuracy that would allow a quick assessment to be made, either giving sufficient information to the operator, or facilitating further investigation. This method paves the way for simple and low cost monitoring of strain and damage 
in composites with applicability in sectors, such as aerospace, power generation, automotive industries.

The authors would like to acknowledge the financial contribution of the Higher Committee for Education Development in Iraq (HCED).

\section{References}

[1] W. Staszewski, C. Boller, G. R. Tomlinson, Health monitoring of aerospace structures: smart sensor technologies and signal processing, John Wiley \& Sons, 2004.

[2] C. R. Farrar, K. Worden, An introduction to structural health monitoring, Philosophical Transactions of the Royal Society A: Mathematical, Physical and Engineering Sciences 365 (1851) (2006) 303-315.

[3] J. Abry, S. Bochard, A. Chateauminois, M. Salvia, G. Giraud, In situ detection of damage in cfrp laminates by electrical resistance measurements, Composites science and technology 59 (6) (1999) 925-935.

[4] R. Matsuzaki, M. Melnykowycz, A. Todoroki, Antenna/sensor multifunctional composites for the wireless detection of damage, Composites Science and Technology 69 (15-16) (2009) 2507-2513.

[5] C. P. Hiremath, K. Senthilnathan, N. Naik, A. Guha, A. Tewari, Microstructural damage based modeling of thermal conductivity of cyclically loaded cfrp, Composites Science and Technology 154 (2018) 37-44.

[6] J. P. McCrory, S. K. Al-Jumaili, D. Crivelli, M. R. Pearson, M. J. Eaton, C. A. Featherston, M. Guagliano, K. M. Holford, R. Pullin, Damage classification in carbon fibre composites using acoustic emission: A comparison of three techniques, Composites Part B: Engineering 68 (2015) 424-430. 
[7] P. Shrestha, Y. Park, C.-G. Kim, Low velocity impact localization on composite wing structure using error outlier based algorithm and fbg sensors, Composites Part B: Engineering 116 (2017) 298-312.

[8] T. Ahmed, G. Nino, H. Bersee, A. Beukers, Heat emitting layers for enhancing nde of composite structures, Composites Part A: Applied Science and Manufacturing 39 (6) (2008) 1025-1036.

[9] D. Bates, G. Smith, D. Lu, J. Hewitt, Rapid thermal non-destructive testing of aircraft components, Composites Part B: Engineering 31 (3) (2000) $175-185$.

[10] P.-y. Hung, K.-t. Lau, L.-k. Cheng, J. Leng, D. Hui, Impact response of hybrid carbon/glass fibre reinforced polymer composites designed for engineering applications, Composites Part B: Engineering 133 (2018) 86-90.

[11] P. W. Beaumont, C. Soutis, Structural integrity of engineering composite materials: a cracking good yarn (2016).

[12] D. Crivelli, M. Guagliano, M. Eaton, M. Pearson, S. Al-Jumaili, K. Holford, R. Pullin, Localisation and identification of fatigue matrix cracking and delamination in a carbon fibre panel by acoustic emission, Composites Part B: Engineering 74 (2015) 1-12.

[13] V. Carvelli, A. D'Ettorre, S. V. Lomov, Acoustic emission and damage mode correlation in textile reinforced pps composites, Composite Structures 163 (2017) 399-409.

[14] B. F. Sørensen, L. Lading, P. Sendrup, M. McGugan, C. P. Debel, O. J. Kristensen, G. C. Larsen, A. M. Hansen, J. Rheinländer, J. Rusborg, et al., Fundamentals for remote structural health monitoring of wind turbine blades-a preproject.

[15] P. Schubel, R. Crossley, E. Boateng, J. Hutchinson, Review of structural health and cure monitoring techniques for large wind turbine blades, Renewable energy 51 (2013) 113-123. 
[16] G. Zhou, L. Sim, Damage detection and assessment in fibre-reinforced composite structures with embedded fibre optic sensors-review, Smart Materials and Structures 11 (6) (2002) 925.

[17] S. Nag-Chowdhury, H. Bellegou, I. Pillin, M. Castro, P. Longrais, J. Feller, Non-intrusive health monitoring of infused composites with embedded carbon quantum piezo-resistive sensors, Composites Science and Technology 123 (2016) 286-294.

[18] T. Liu, M. Wu, Y. Rao, D. A. Jackson, G. F. Fernando, A multiplexed optical fibre-based extrinsic fabry-perot sensor system for in-situ strain monitoring in composites, Smart materials and structures 7 (4) (1998) 550.

[19] J. Leng, A. Asundi, Structural health monitoring of smart composite materials by using efpi and fbg sensors, Sensors and Actuators A: Physical 103 (3) (2003) 330-340.

[20] L. M. Chiacchiarelli, M. Rallini, M. Monti, D. Puglia, J. M. Kenny, L. Torre, The role of irreversible and reversible phenomena in the piezoresistive behavior of graphene epoxy nanocomposites applied to structural health monitoring, Composites Science and Technology 80 (2013) 73-79.

[21] A. D. B. Ferreira, P. R. Novoa, A. T. Marques, Multifunctional material systems: a state-of-the-art review, Composite Structures 151 (2016) 3-35.

[22] N. Hu, H. Fukunaga, S. Atobe, Y. Liu, J. Li, et al., Piezoresistive strain sensors made from carbon nanotubes based polymer nanocomposites, Sensors 11 (11) (2011) 10691-10723.

[23] E. T. Thostenson, T.-W. Chou, Real-time in situ sensing of damage evolution in advanced fiber composites using carbon nanotube networks, Nanotechnology 19 (21) (2008) 215713.

[24] J. Baur, E. Silverman, Challenges and opportunities in multifunctional nanocomposite structures for aerospace applications, MRS bulletin 32 (4) (2007) 328-334. 
[25] R. F. Gibson, A review of recent research on mechanics of multifunctional composite materials and structures, Composite structures 92 (12) (2010) $2793-2810$.

[26] L. Hou, S. Hayes, A resistance-based damage location sensor for carbonfibre composites, Smart Materials and Structures 11 (6) (2002) 966.

[27] B. Ellis, et al., Chemistry and technology of epoxy resins, Springer, 1993.

[28] M. S. Dresselhaus, G. Dresselhaus, K. Sugihara, I. L. Spain, H. A. Goldberg, Graphite fibers and filaments, Vol. 5, Springer Science \& Business Media, 2013.

[29] V. Antonucci, M. Giordano, L. Nicolais, A. Calabro, A. Cusano, A. Cutolo, S. Inserra, Resin flow monitoring in resin film infusion process, Journal of Materials Processing Technology 143 (2003) 687-692.

[30] M. Danisman, G. Tuncol, A. Kaynar, E. M. Sozer, Monitoring of resin flow in the resin transfer molding ( $\mathrm{rtm}$ ) process using point-voltage sensors, Composites Science and Technology 67 (3-4) (2007) 367-379.

[31] R. Matsuzaki, S. Kobayashi, A. Todoroki, Y. Mizutani, Full-field monitoring of resin flow using an area-sensor array in a vartm process, Composites Part A: Applied Science and Manufacturing 42 (5) (2011) 550-559.

[32] M. G. Sause, Combination of methods, in: In Situ Monitoring of FiberReinforced Composites, Springer, 2016, pp. 533-609.

[33] E. Oromiehie, B. G. Prusty, P. Compston, G. Rajan, Characterization of process-induced defects in automated fiber placement manufacturing of composites using fiber bragg grating sensors, Structural Health Monitoring 17 (1) (2018) 108-117.

[34] S. H. Foulger, Electrical properties of composites in the vicinity of the percolation threshold, Journal of Applied Polymer Science 72 (12) (1999) $1573-1582$. 
[35] A. Todoroki, M. Tanaka, Y. Shimamura, Measurement of orthotropic electric conductance of cfrp laminates and analysis of the effect on delamination monitoring with an electric resistance change method, Composites Science and Technology 62 (5) (2002) 619-628.

[36] J. Abry, Y. Choi, A. Chateauminois, B. Dalloz, G. Giraud, M. Salvia, In-situ monitoring of damage in cfrp laminates by means of ac and dc measurements, Composites Science and Technology 61 (6) (2001) 855-864.

[37] O. Ceysson, M. Salvia, L. Vincent, Damage mechanisms characterisation of

- carbon fibre/epoxy composite laminates by both electrical resistance mea-

$575 \quad$ surements and acoustic emission analysis, Scripta Materialia 34 (8) (1996) 1273 - 1280. doi:https://doi.org/10.1016/1359-6462(95)00638-9.

1. URL http://www.sciencedirect.com/science/article/pii/ 1359646295006389

[38] K. Schulte, , C. Baron, Load and failure analyses of cfrp laminates by means of electrical resistivity measurements, Composites science and technology 36 (1) (1989) 63-76.

[39] M. Kemp, Self-sensing composites for smart damage detection using electrical properties, in: Second European Conference on Smart Structures and Materials, Vol. 2361, International Society for Optics and Photonics, 1994, pp. $136-140$.

[40] A. Todoroki, K. Omagari, Y. Shimamura, H. Kobayashi, Matrix crack detection of cfrp using electrical resistance change with integrated surface probes, Composites science and technology 66 (11-12) (2006) 1539-1545.

[41] S. Wang, D. Chung, Piezoresistivity in continuous carbon fiber polymer590 matrix composite, Polymer Composites 21 (1) (2000) 13-19.

[42] S. Wang, D. Wang, D. Chung, J. H. Chung, Method of sensing impact damage in carbon fiber polymer-matrix composite by electrical resistance measurement, Journal of materials science 41 (8) (2006) 2281-2289. 
[43] J. Gadomski, P. Pyrzanowski, Experimental investigation of fatigue destruction of cfrp using the electrical resistance change method, Measurement 87 (2016) 236-245.

[44] P. Irving, C. Thiagarajan, Fatigue damage characterization in carbon fibre composite materials using an electrical potential technique, Smart materials and structures 7 (4) (1998) 456.

[45] T. Swait, F. Jones, S. Hayes, A practical structural health monitoring system for carbon fibre reinforced composite based on electrical resistance, Composites Science and Technology 72 (13) (2012) 1515-1523.

[46] R. J. Hart, O. Zhupanska, Influence of low-velocity impact-induced delamination on electrical resistance in carbon fiber-reinforced composite laminates, Journal of Composite Materials (2018) 0021998318776361.

[47] M. Zappalorto, F. Panozzo, P. A. Carraro, M. Quaresimin, Electrical response of a laminate with a delamination: modelling and experiments, Composites Science and Technology 143 (2017) 31-45.

[48] V. I. Livshits, V. I. Golovin, V. I. Meshkov, Process for manufacturing panels to be used in microelectronic systems, uS Patent 4,404,059 (Sep. 13 1983).

[49] M. W. Jawitz, Printed circuit board materials handbook (electronic packaging and interconnection), McGraw-Hill, New York, 1997.

[50] Association Connecting Electronics Industries, IPC-TM-650, e (4 2014).

${ }_{615}[51]$ R. A. Naik, Failure analysis of woven and braided fabric reinforced composites, Journal of Composite Materials 29 (17) (1995) 2334-2363.

[52] Torayca Carbon Fibres America, Inc., T300 carbon fibre technical data sheet, e (4 2014).

[53] Formosa Plastic Corporation, Tairyfill carbon fibre data sheet (2012). 
[54] C. Owston, Electrical properties of single carbon fibres, Journal of Physics D: Applied Physics 3 (11) (1970) 1615.

[55] X. Wang, D. Chung, Self-monitoring of fatigue damage and dynamic strain in carbon fiber polymer-matrix composite, Composites Part B: Engineering 29 (1) (1998) 63-73.

${ }_{625}$ [56] J. Wen, Z. Xia, F. Choy, Damage detection of carbon fiber reinforced polymer composites via electrical resistance measurement, Composites Part B: Engineering 42 (1) (2011) 77-86.

[57] S. G. Advani, K.-T. Hsiao, Manufacturing techniques for polymer matrix composites (PMCs), Elsevier, 2012.

${ }_{630}$ [58] P. Hubert, G. Fernlund, A. Poursartip, Autoclave processing for composites, in: Manufacturing techniques for polymer matrix composites (PMCs), Elsevier, 2012, pp. 414-434.

[59] EasyComposites-ltd, In-2 epoxy infusion resin.

[60] A. C. Long, Design and manufacture of textile composites, Elsevier, 2005.

${ }_{635}$ [61] S. Rana, R. Fangueiro, Advanced composite materials for aerospace engineering: Processing, properties and applications, Woodhead Publishing, 2016.

[62] L. Vertuccio, L. Guadagno, G. Spinelli, P. Lamberti, V. Tucci, S. Russo, Piezoresistive properties of resin reinforced with carbon nanotubes for health-monitoring of aircraft primary structures, Composites Part B: Engineering 107 (2016) 192-202.

[63] A. Sanli, A. Benchirouf, C. Müller, O. Kanoun, Piezoresistive performance characterization of strain sensitive multi-walled carbon nanotube-epoxy nanocomposites, Sensors and Actuators A: Physical 254 (2017) 61-68.

${ }_{645}$ [64] D. Chung, Structural health monitoring by electrical resistance measurement, Smart materials and structures 10 (4) (2001) 624. 

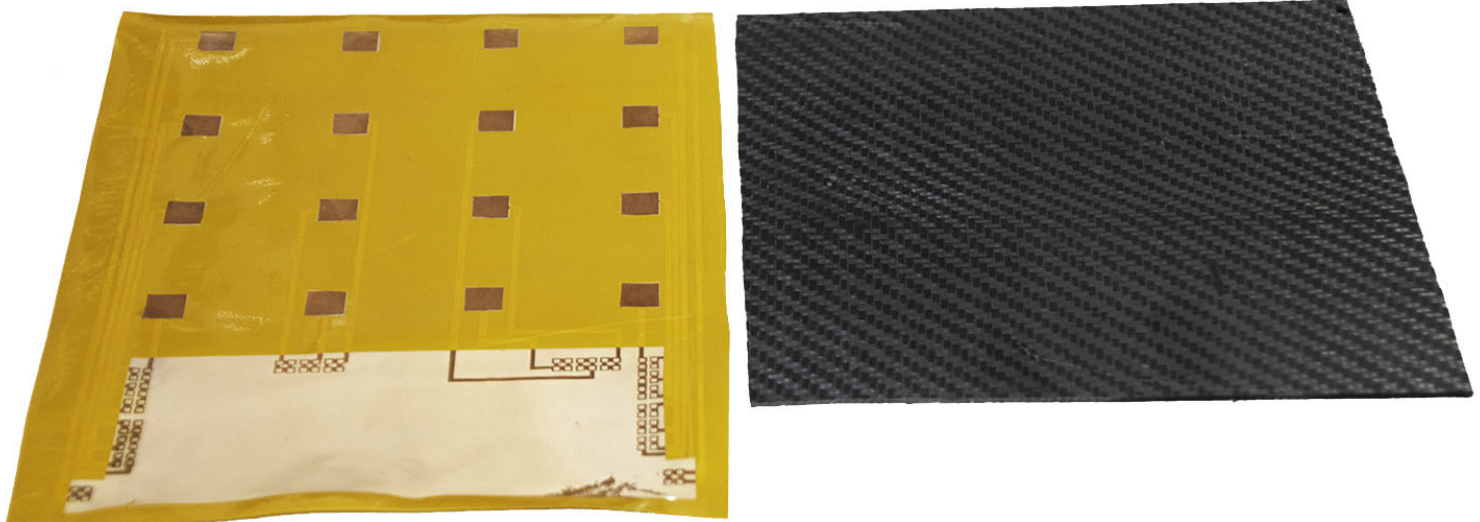

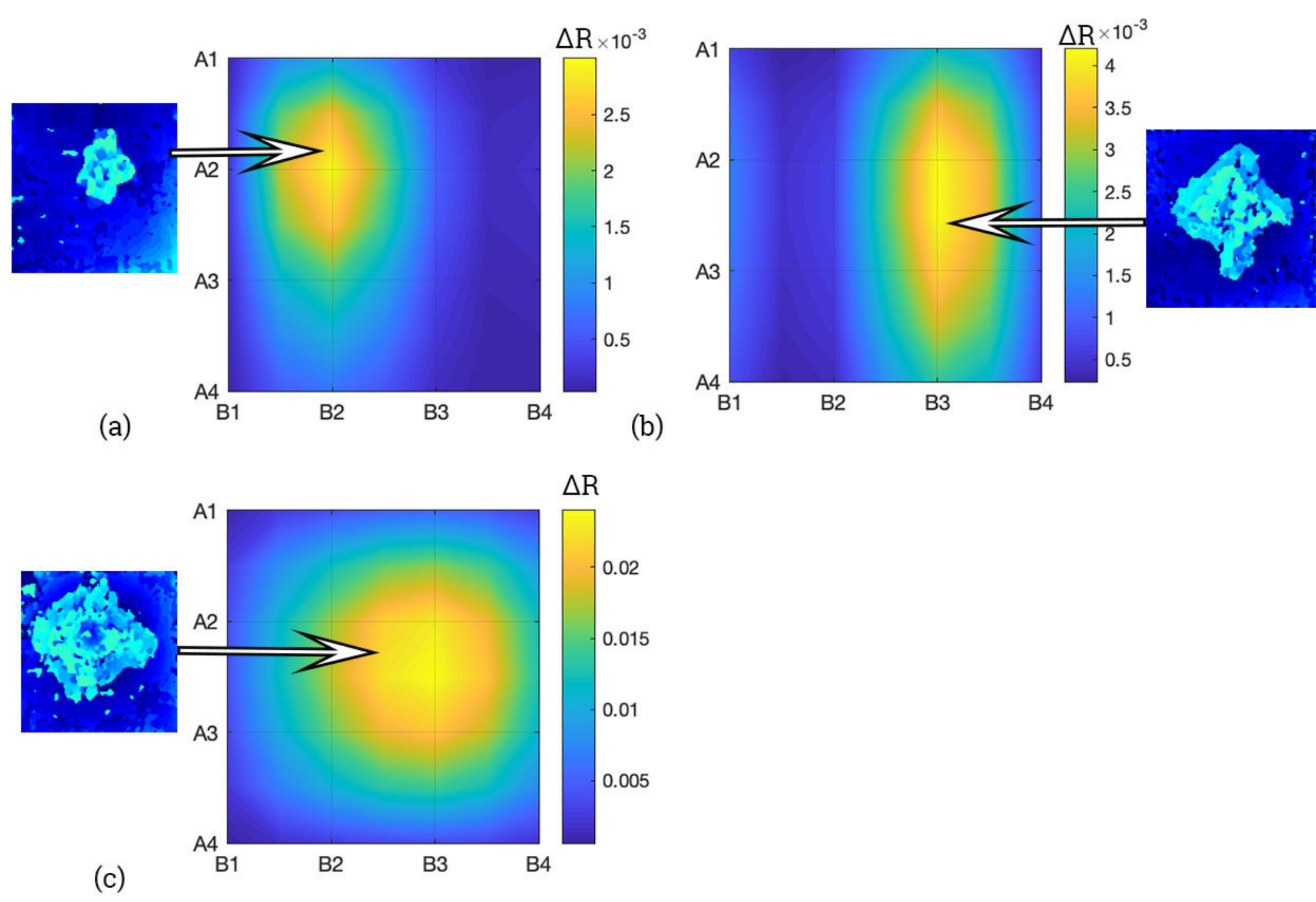


\section{$A \Delta$}

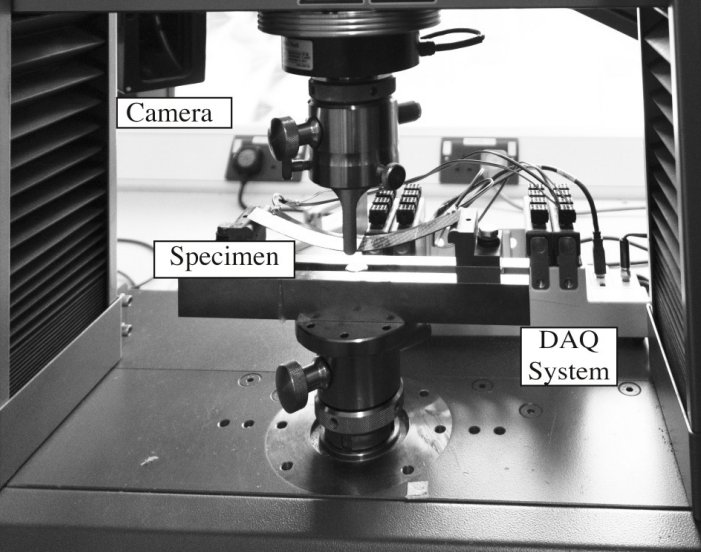


Granular Sheet-like Random structure structure structure

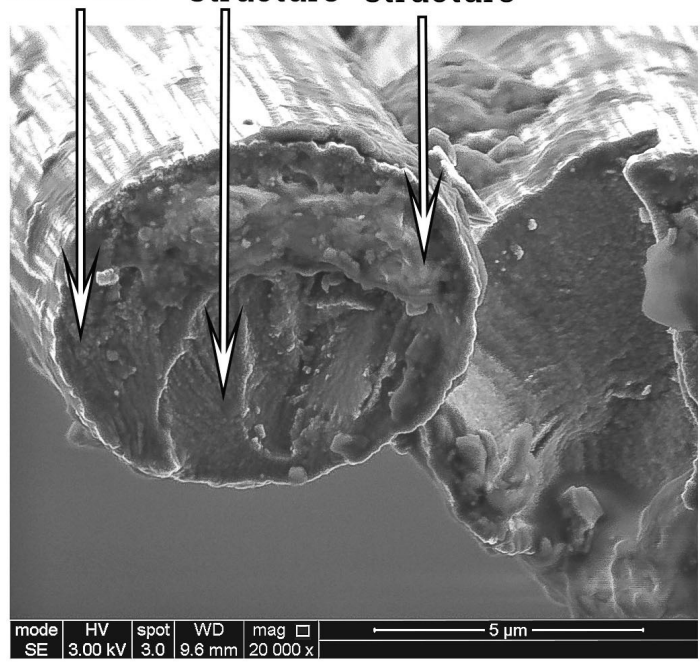

(a)
Particulate of granular

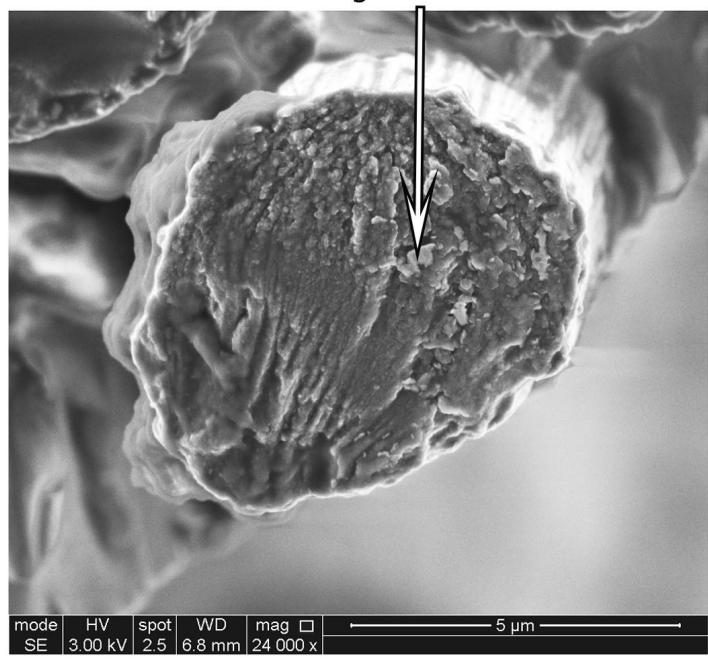

(b) 


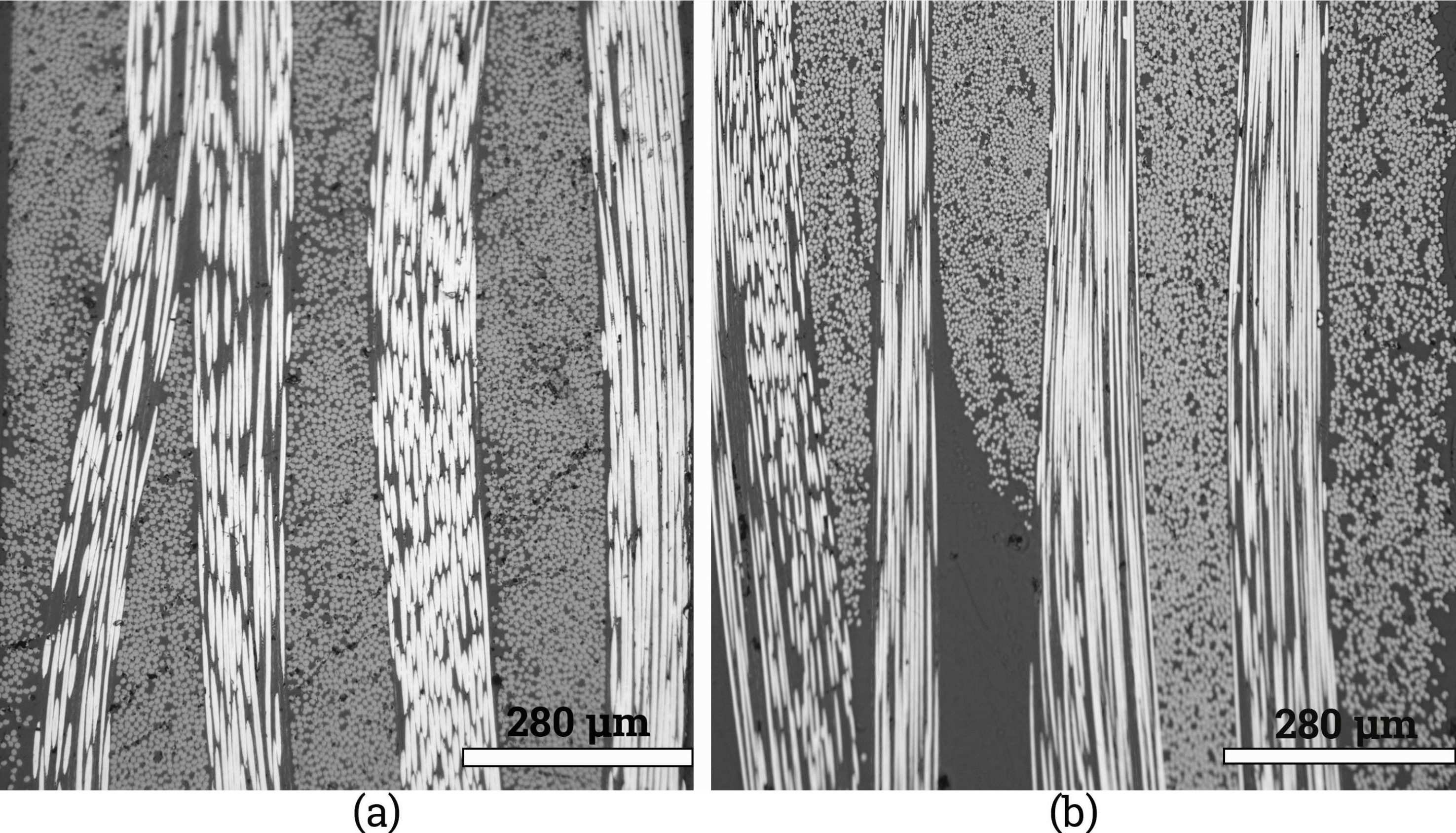




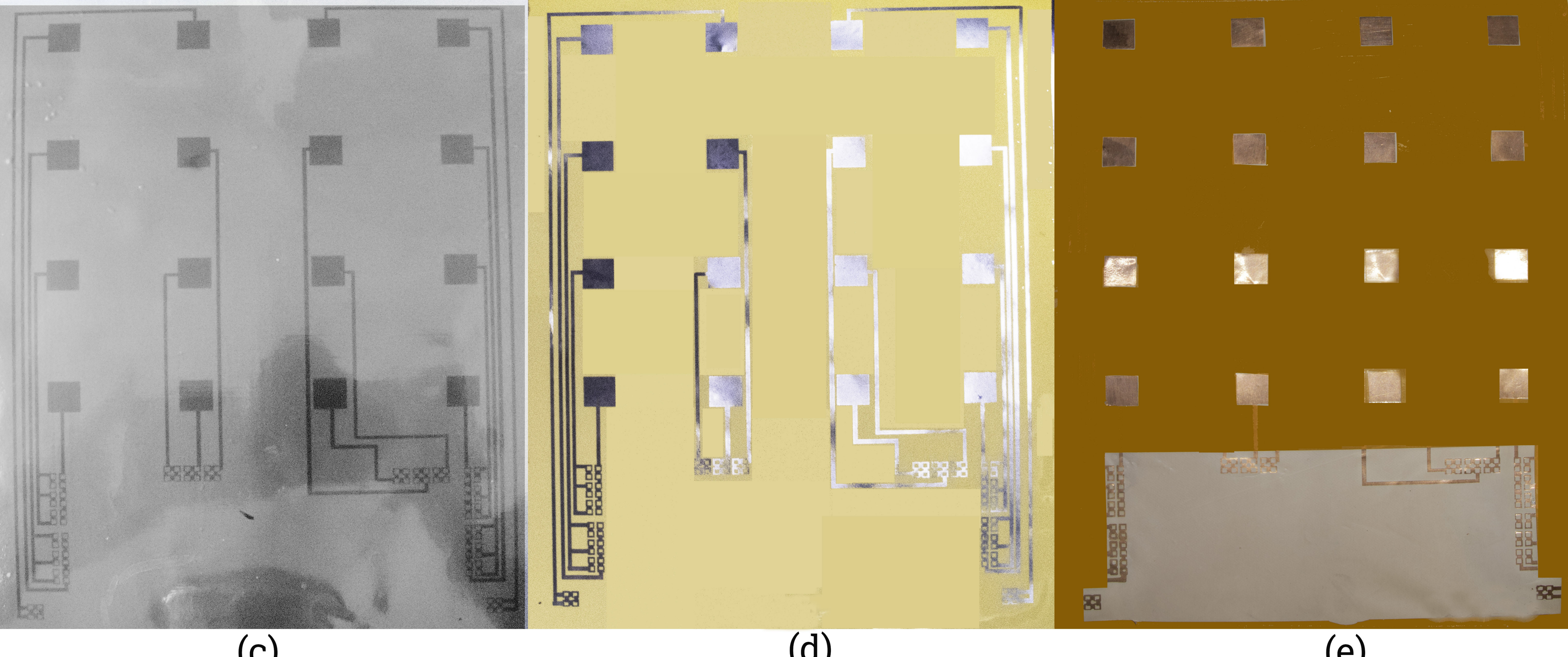

(c)

(d)

(e) 


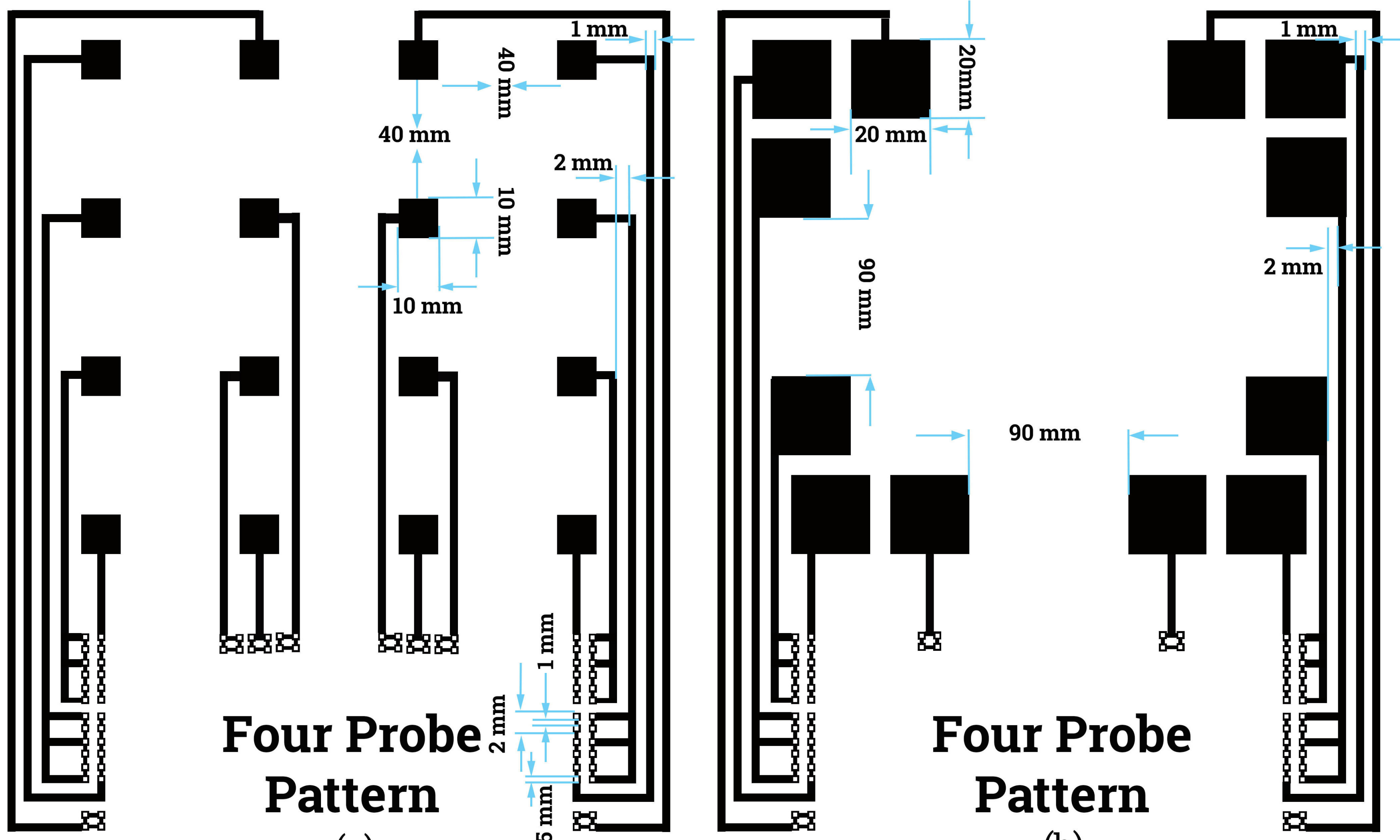

(a)

(b) 


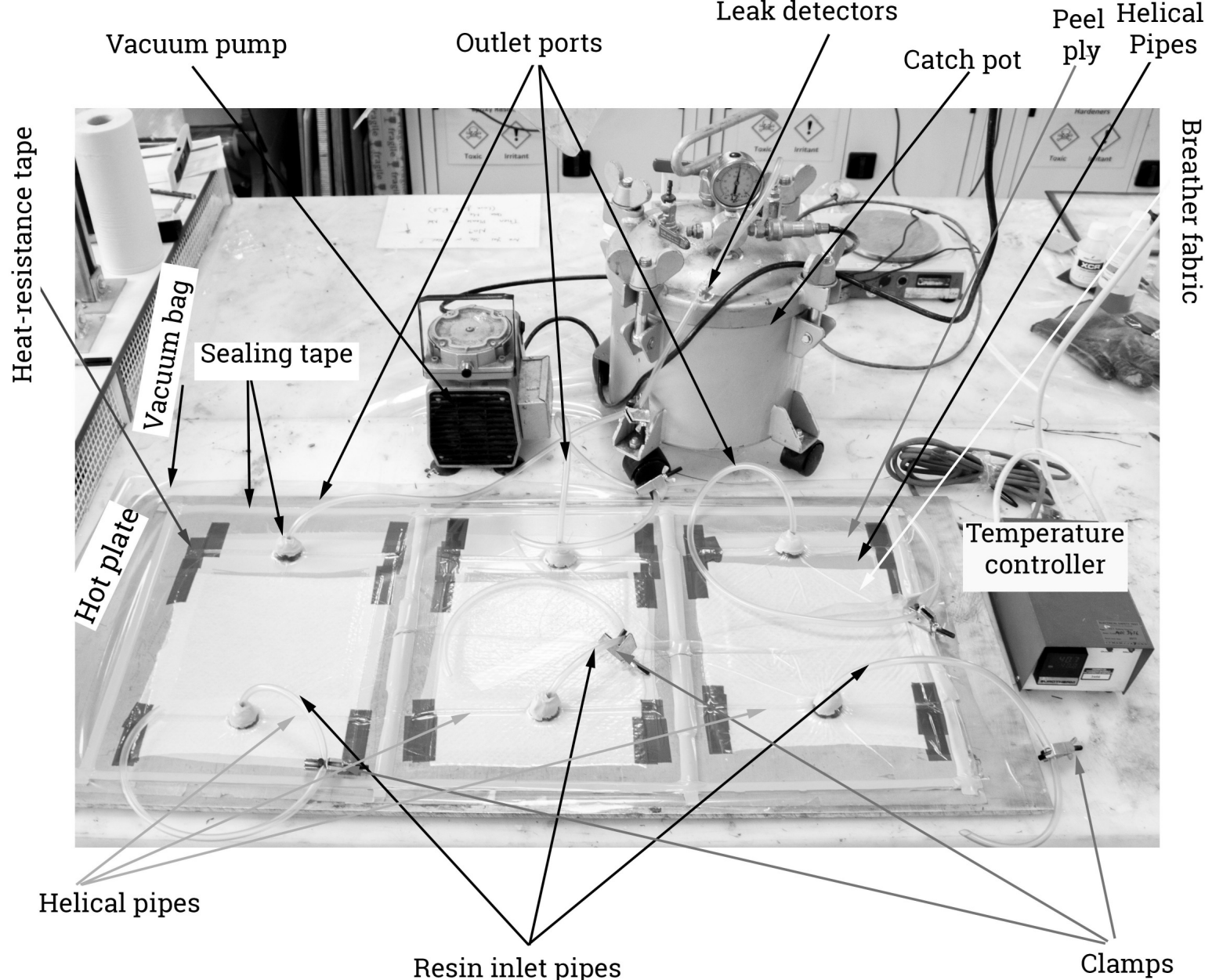



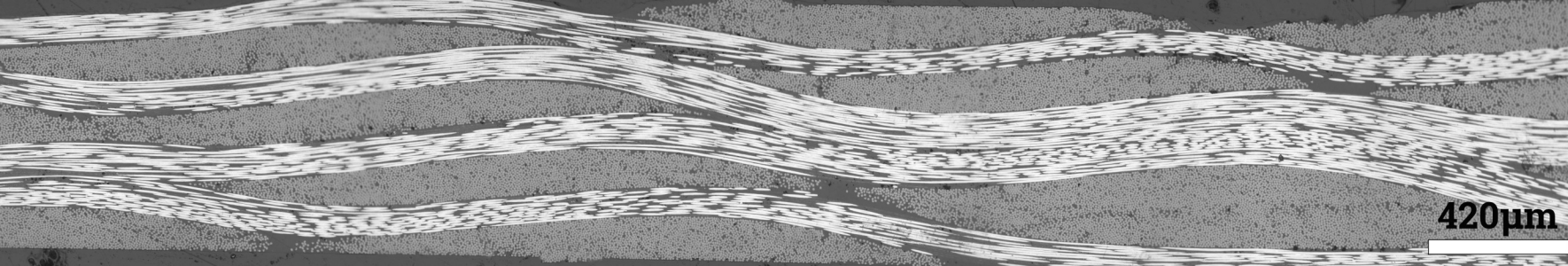


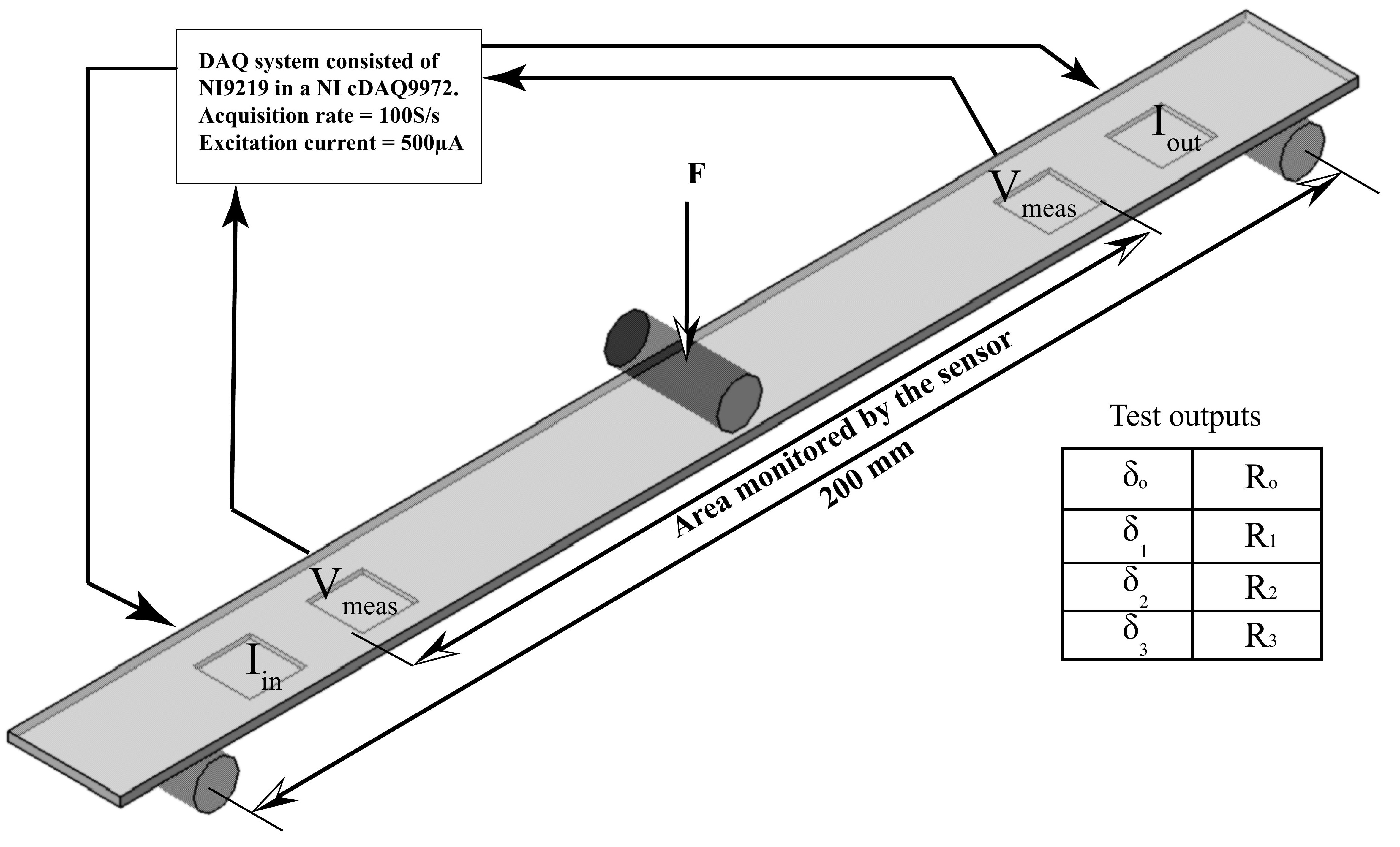




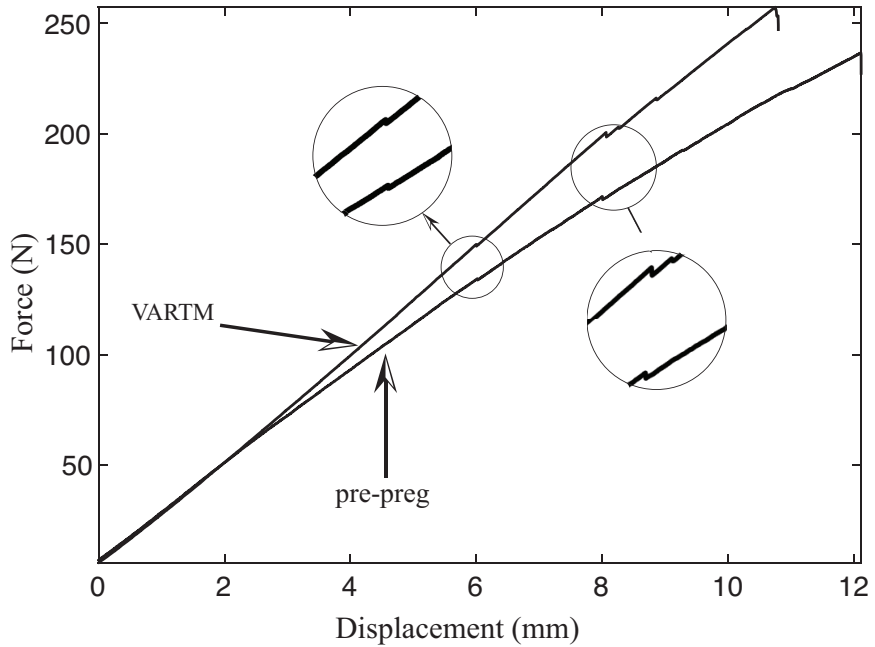


- Autoclave mat $1 \triangleleft$ Autoclave mat $2 \diamond$ VARTM mat $1 \triangleright$ VARTM mat 2

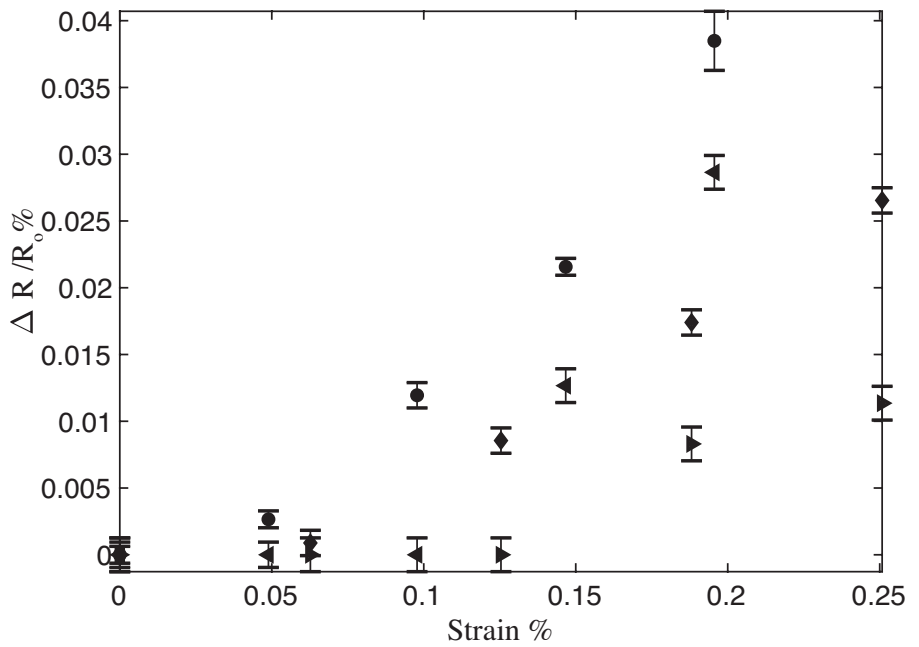




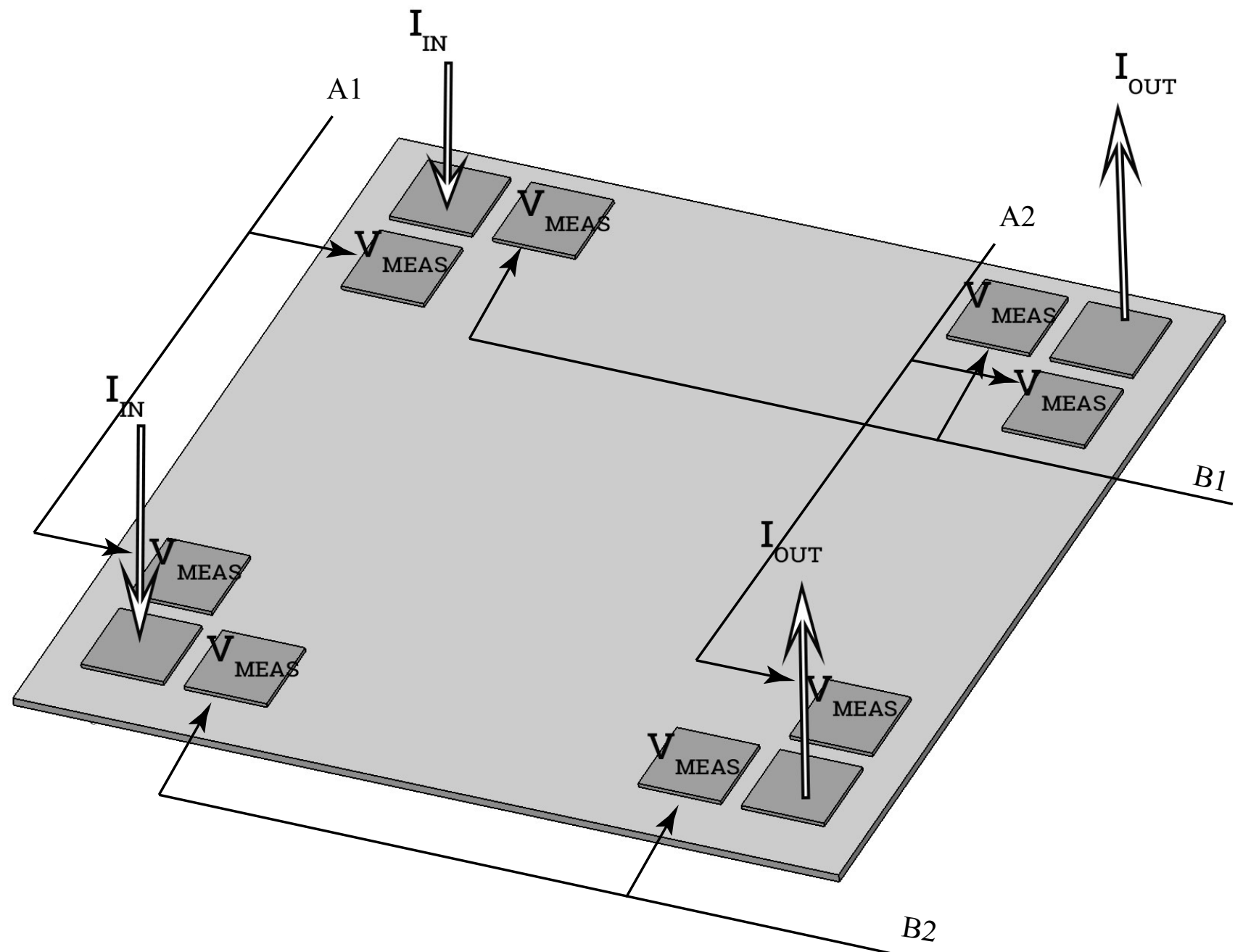




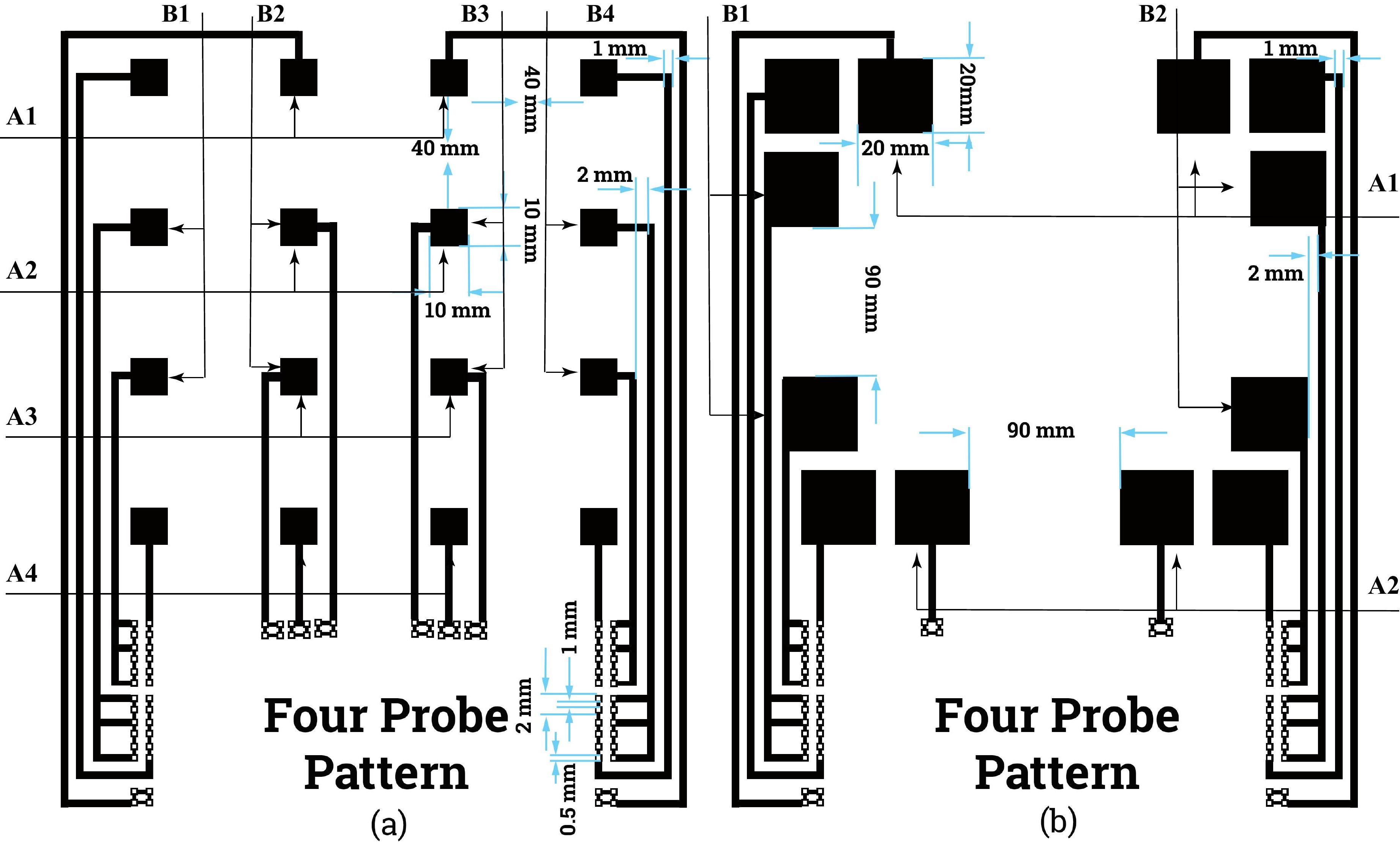




\section{$\quad$ Mat $1 \quad \diamond \quad$ Mat $2 \longrightarrow$ Fitting line}

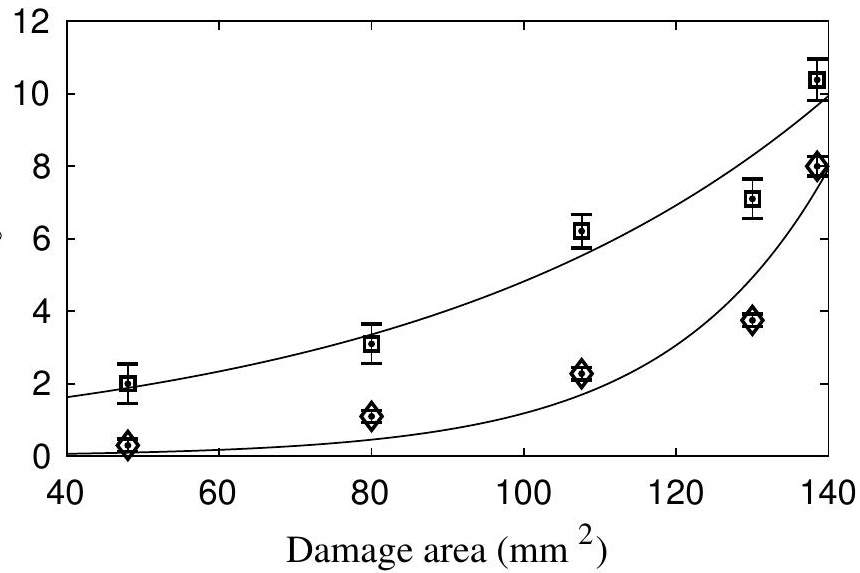




\section{$\triangleleft$ Mat $1 \quad \triangleright \quad$ Mat $2 \longrightarrow$ Fitting line}

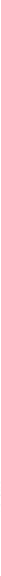

